\title{
Gas phase precursors to anthropogenic secondary organic aerosol: detailed observations of 1,3,5-trimethylbenzene photooxidation
}

\author{
K. P. Wyche ${ }^{1}$, P. S. Monks ${ }^{1}$, A. M. Ellis ${ }^{1}$, R. L. Cordell ${ }^{1}$, A. E. Parker ${ }^{1}$, C. Whyte ${ }^{1}$, A. Metzger ${ }^{2}$, J. Dommen ${ }^{2}$, \\ J. Duplissy ${ }^{2}$, A. S. H. Prevot ${ }^{2}$, U. Baltensperger ${ }^{2}$, A. R. Rickard ${ }^{3}$, and F. Wulfert ${ }^{4}$ \\ ${ }^{1}$ Atmospheric Chemistry, Department of Chemistry, University of Leicester, Leicester, LE1 7RH, UK \\ ${ }^{2}$ Laboratory of Atmospheric Chemistry, Paul Scherrer Institut, 5232, Villigen, Switzerland \\ ${ }^{3}$ National Centre for Atmospheric Science, University of Leeds, Leeds, LS2 9JT, UK \\ ${ }^{4}$ Division of Food Sciences, University of Nottingham, Sutton Bonington Campus, Loughborough, LE12 5RD, UK
}

Received: 15 April 2008 - Published in Atmos. Chem. Phys. Discuss.: 13 June 2008

Revised: 1 December 2008 - Accepted: 1 December 2008 - Published: 27 January 2009

\begin{abstract}
A series of photooxidation experiments were conducted in an atmospheric simulation chamber in order to investigate the oxidation mechanism and secondary organic aerosol (SOA) formation potential of the model anthropogenic gas phase precursor, 1,3,5-trimethylbenzene. Alongside specific aerosol measurements, comprehensive gas phase measurements, primarily by Chemical Ionisation Reaction Time-of-Flight Mass Spectrometry (CIR-TOFMS), were carried out to provide detailed insight into the composition and behaviour of the organic components of the gas phase matrix during SOA formation. An array of gas phase organic compounds was measured during the oxidation process, including several previously unmeasured primary bicyclic compounds possessing various functional groups. Analysis of results obtained during this study implies that these peroxide bicyclic species along with a series of ring opening products and organic acids contribute to SOA growth. The effect of varying the $\mathrm{VOC} / \mathrm{NO}_{\mathrm{x}}$ ratio on SOA formation was explored, as was the effect of acid seeding. It was found that low $\mathrm{NO}_{\mathrm{x}}$ conditions favour more rapid aerosol formation and a higher aerosol yield, a result that implies a role for organic peroxides in the nucleation process and SOA growth.
\end{abstract}

\section{Introduction}

Secondary organic aerosol (SOA) is formed in the atmosphere from the oxidation products of certain biogenic

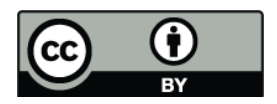

Correspondence to: P. S. Monks (p.s.monks@le.ac.uk) and anthropogenic volatile organic compounds (VOCs) (Finlayson-Pitts and Pitts Jr., 2000). One important class of such compounds known to be precursors to SOA are aromatic hydrocarbons (Stern et al., 1987; Odum et al., 1997). Possessing complex and extensive atmospheric reaction pathways, aromatic VOCs (AVOCs) have the ability to yield a wide array of secondary oxygenated and nitrated volatile, semi-volatile and non-volatile organic products which contain a multitude of different functional groups (e.g. Atkinson, 2000; Hamilton et al., 2003; Johnson et al., 2005; Sax et al., 2005; Bloss et al., 2005b).

Released principally from automobile exhaust emissions, industrial scale combustion and the evaporation of fuels and solvents (Friedrich and Obermeier, 1999), AVOCs make up as much as $40 \%$ of the total mass of anthropogenic hydrocarbon emissions in the city environment (Smith et al., 1999). On the global scale total aromatic emissions are of the order $15.8 \mathrm{Tg}^{-1}$ (Tsigaridis and Kanakidou, 2003), which accounts for $\sim 15 \%$ of the annual anthropogenic non-methane hydrocarbon (NMHC) budget (Bloss et al., 2005a). As well as constituting precursors to SOA production, AVOCs generally have high photochemical ozone creation potentials and hence contribute significantly towards tropospheric ozone pollution (Calvert et al., 2002; Derwent et al., 2003, 2007a, 2007b).

It has been established that SOA mass constitutes a major fraction of the total atmospheric loading of organic aerosol and indeed the more general class of atmospheric particulate matter, on both the local (Baltensperger et al., 2005) and the global (Kanakidou et al., 2005) scale. Under certain scenarios atmospheric SOA can comprise as much as $90 \%$ of organic aerosol mass (Kalberer et al., 2004) and 50\% of the total mass of atmospheric aerosol (Kleindienst et al., 1999).

Published by Copernicus Publications on behalf of the European Geosciences Union. 
The existence of SOA in the atmosphere (and particulate matter in general) has an array of well documented consequences (e.g. Czoschke et al., 2003; Kanakidou et al., 2005; IPCC, 2007 and references therein). In brief, such negative effects range from visibility impairment on the local scale to climate change, with SOA being capable of perturbing the Earth's radiative budget via both direct and indirect mechanisms. Additionally, fine airborne particles have been shown to exert numerous detrimental effects on human health, particularly in vulnerable members of the population (Grosjean, 1992).

As highlighted in recent reviews (e.g. Seinfeld and Pankow, 2003; Kanakidou et al., 2005; Holmes, 2007), despite its crucial impact upon the Earth-atmosphere system, there currently remains a certain lack of understanding regarding the physical and chemical properties of SOA, its chemical composition and crucially the atmospheric processes by which it is formed.

Over the last decade much research and many state of the art techniques have been applied to the critical problem of determining SOA chemical composition, with off-line GCMS analysis of filter samples often providing the foundation. However, such studies have supplied limited molecular level classification, with generally no more than $30 \%$ of the total SOA mass being identified (e.g. Forstner et al., 1997; Kleindienst et al., 1999; Cocker III et al., 2001; Hamilton et al., 2003; Edney et al., 2005; Surratt et al., 2006).

A series of recent discoveries have allowed significant advancement to be made in our understanding of SOA composition and the role of relatively low molecular mass species in aerosol growth. It has been proposed that between 20 and $50 \%$ of SOA mass could be comprised of large multi-functional macromolecular compounds known as "humic-like substances" (HULIS) (Havers et al., 1998), which would go undetected using standard GC-MS techniques. Research has suggested that such compounds are secondary in nature, being formed by heterogeneous polymerisation/oligomerisation reactions in the aerosol. For example, Jang and Kamens (Jang and Kamens, 2001) witnessed an increase in SOA yield when various gas phase aldehyde compounds were injected into a synthetic air matrix impregnated with acidic seed particles. The authors attribute the increase in SOA mass to heterogeneous hydration and polymerisation reactions of low molecular mass aldehydes following their transfer from the gas phase. Their findings also indicated that hemiacetal/acetal formation is also an important contributing pathway to increased SOA yields when alcohols were also present.

Numerous investigations have since confirmed the existence of polymeric/oligomeric compounds in various SOA systems of both anthropogenic (Gross et al., 2006) and biogenic (Surratt et al., 2006) origin, both in simulation chamber studies (Baltensperger et al., 2005) and in the "real" atmosphere (Kalberer et al., 2006), with molecular masses as large as $1600 \mathrm{Da}$ (Gao et al., 2004). One such study by
Kalberer et al. (2004) demonstrated that as much as $50 \%$ of the SOA mass formed during the photooxidation of 1,3,5trimethylbenzene was composed of polymers (Kalberer et al., 2004). The authors proposed that the polymers, which were detected with masses as high as $1000 \mathrm{Da}$, were formed primarily through acetal polymerisation involving the known trimethylbenzene photooxidation product methyl glyoxal in the presence of water.

With a large portion of current research into SOA formation geared towards investigation of the aerosol phase, there exists a distinct lack of detailed understanding of the concomitant gas phase organic components of the system. Indeed limited work has been conducted to help illuminate the actual mechanisms of SOA formation from the view point of the gas phase. Recently, research has shown that the SOA forming capacity of aromatic systems is strongly related to the gas phase $\left[\mathrm{NO}_{\mathrm{x}}\right]$, with greater SOA yields obtained under low $\mathrm{NO}_{\mathrm{x}}$ conditions (Izumi et al., 1988; Stroud et al., 2004; Song et al., 2005; Ng et al., 2007). Conclusions drawn from such work infer an important role for gas phase organic peroxides in initiating the formation of SOA (Johnson et al., 2004), but no direct evidence is available to support this.

In the present study we begin to address these issues by presenting findings from a series of comprehensive photooxidation experiments conducted in an atmospheric simulation chamber. The main aim of the study was to monitor, in detail and with good temporal resolution, the complex array of gaseous organic oxidation products derived from known SOA precursors, and in doing so elucidate underlying degradation mechanisms and identify potential species contributing to incipient aerosol formation and growth. In this instance the common, but less well studied anthropogenic AVOC, 1,3,5-trimethylbenzene (TMB) was chosen as a model anthropogenic SOA precursor. The effect of variation of the initial $\mathrm{VOC} / \mathrm{NO}_{\mathrm{x}}$ ratio on SOA formation was explored, as was the potential role of acid-catalysed heterogeneous chemistry. As well as presenting information that provides new insight into the mechanisms of SOA forming intermediates and potential SOA forming species, this work presents the first measurements of a set of previously undetected high mass oxygen-bridged bicyclic compounds, which are formed during aromatic oxidation.

In a companion article (here after referred to as Rickard et al., 2008) the gas phase measurements presented here are compared with the output of a box model employing data extracted from the Master Chemical Mechanism (MCMv3.1; http://mcm.leeds.ac.uk/MCM). The findings of this complementary study support the results obtained here and in combination they provide further insight into the identity of potential SOA forming species. 


\section{Experimental}

\subsection{The Paul Scherrer Institut aerosol chamber}

Experiments were carried out at the Paul Scherrer Institut aerosol chamber facility (Ch.). The chamber comprises a single-lined collapsible bag constructed from DuPont fluorinated ethylene propylene (FEP) film, with a wall thickness of $125 \mu \mathrm{m}$ and a volume of $27 \mathrm{~m}^{3}\left(3 \times 3 \times 3 \mathrm{~m}^{3}\right)$. The chamber surface area to volume ratio $\left(2 \mathrm{~m}^{-1}\right)$ is relatively small when compared to most environment chambers, allowing wall effects to be minimized. The chamber bag is held by a large metal frame inside a temperature-controlled wooden housing, which was maintained at $20^{\circ} \mathrm{C}\left( \pm 1^{\circ} \mathrm{C}\right)$ during all experiments. Four $4 \mathrm{~kW}$ xenon arc lamps, deployed at various points inside the housing were employed to simulate the solar spectrum (Paulsen et al., 2005).

The chamber sample gas comprised purified ambient air, which was produced by a clean air generator (AADCO Instruments Inc., USA). Chamber humidification was facilitated by bubbling the bulk matrix gas through a heated glass vessel containing high purity deionized water $(15 \mathrm{M} \Omega$ ) prior to the injection of other compounds. The chamber humidity was typically near $50 \%$ during each experiment.

Delivery of the VOC SOA precursor to the chamber took place via syringe injection of the liquid compound into a heated injector port, which facilitated compound volatilisation before entry into the bag. A period of $30 \mathrm{~min}$ was allowed for mixing to create a homogeneous sample matrix before any measurements were made. The chamber does not employ fan assisted mixing.

In order to remove any potential organic impurities from the chamber and hence to eliminate unwanted artefacts from the data (in the form of SOA formed from species other than the TMB), the chamber bag was scrubbed with ozone (2$7 \mathrm{ppmV}$ ) for $5 \mathrm{~h}$, before being flushed thoroughly with purified ambient air for approximately $30 \mathrm{~h}$ prior to each experiment.

On-line measurements of chamber nitric oxide (NO) and $\mathrm{NO}_{\mathrm{x}}$ concentrations were made throughout each experiment using a Monitor Labs 9841A $\mathrm{NO}_{\mathrm{x}}$ analyser (for $\mathrm{NO}_{\mathrm{x}}$ concentrations: $50-2000 \mathrm{ppbV}$ ) and a Thermo Environmental Instruments $42 \mathrm{C}$ trace level $\mathrm{NO}_{\mathrm{x}}$ photolytic converter (for $\mathrm{NO}_{\mathrm{x}}$ concentrations: 0-200 ppbV). Ozone measurements were also conducted in real-time using an ozone analyser (Environics model S300). The aerosol phase was monitored using two TSI (3025 and 3022A) condensation particle counters (CPC, size range: particle diameter $\left(D_{p}\right) \geq 3 \mathrm{~nm}$ ) and a Sampling Mobility Particle Sizer (SMPS, size range: $15 \leq \mathrm{D}_{p} \leq 690 \mathrm{~nm}$ ), providing information on the total number density of particles in the chamber along with particle geometric mean diameter and aerosol volume concentration (see Dommen et al., 2006 for further instrument details).

\subsection{Experiment design}

In order to explore the effect of $\mathrm{NO}_{\mathrm{x}}$ on the TMB-SOA system, experiments were conducted with various initial $\mathrm{VOC} / \mathrm{NO}_{\mathrm{x}}$ ratios. For the first part of the study, chamber experiments were conducted with high concentrations of VOC ( $>500 \mathrm{ppbV})$ and $\mathrm{NO}_{\mathrm{x}}(>250 \mathrm{ppbV})$. For these "high $\mathrm{NO}_{\mathrm{x}}$ " experiments nitric oxide and nitrogen dioxide $\left(\mathrm{NO}_{2}\right)$ gases (Air Liquide, Ch., grade N6.0) were added to the chamber via an inlet injection system prior to introduction of the VOC. Experiments with initial $\mathrm{VOC} / \mathrm{NO}_{\mathrm{x}}$ ratios of approximately 2:1, 2:1 (with NO only) and 1:2 were carried out during the high $\mathrm{NO}_{\mathrm{x}}$ part of the study.

As well as conducting high $\mathrm{NO}_{\mathrm{x}}$ chamber experiments with input of all gases to the chamber before initiation of the photochemistry, two "low $\mathrm{NO}_{\mathrm{x}}$ " concentration experiments were conducted in order to simulate more realistic atmospheric conditions. In these experiments a constant low level source of nitrous acid (HONO) was used to supply $\mathrm{NO}$ to the system in place of $\mathrm{NO}$ and $\mathrm{NO}_{2}$ gases. $\mathrm{HONO}$ was produced by reaction of a sodium nitrite solution with sulphuric acid in a flow system. A nitrogen carrier gas was passed through the mixture continuously in order to purge nitrous acid vapour out and into the chamber bag (Taira and Yukio, 1990). This process provided a constant HONO mixing ratio of roughly $10 \mathrm{ppbV}$ throughout each low $\mathrm{NO}_{\mathrm{x}}$ experiment. Consequently, the low concentration experiments had high initial $\mathrm{VOC} / \mathrm{NO}_{\mathrm{x}}$ ratios of $\sim 16: 1$. In order to provide a brief exploration into the effect of an inorganic seed, for experiment 7 (see below), $400 \mathrm{pptV}$ sulphur dioxide $\left(\mathrm{SO}_{2}\right)$ gas was added to the chamber. Table 1 lists the specific starting conditions used for each experiment.

\subsection{VOC/OVOC measurement with chemical ionisation re- action time-of-flight mass spectrometry}

The gas phase organic compounds within the chamber were monitored using a newly developed chemical ionisation reaction time-of-flight mass spectrometer (CIR-TOF-MS). TOFMS comes into its own when dealing with such complex mixtures since the entire spectrum is captured in any one instant. Furthermore, the technique is not constrained by upper mass limits and its standard resolution is usually far higher than more conventional quadrupole mass spectrometers. Therefore, important advantages of CIR-TOF-MS in this instance include the ability to detect a comprehensive set of organic compounds, including oxygenated VOCs (OVOCs) and species of relatively high molecular mass, and the ability to assist compound identification on the basis of accurate (i.e. exact) mass measurements. Details regarding the instrument and its performance have been given previously (Blake et al., 2003; Wyche et al., 2007), and hence only a brief and experiment-specific review is provided here.

The CIR-TOF-MS comprises a radioactive ion source/drift cell assembly, coupled to an orthogonal time-of-flight mass 
Table 1. Summary of the major gas phase parameters for experiments 1-7 along with specific CIR-TOF-MS conditions employed for VOC monitoring.

\begin{tabular}{|c|c|c|c|c|c|c|c|c|c|}
\hline $\begin{array}{l}\text { Exp. } \\
\text { No. }\end{array}$ & $\begin{array}{c}\text { Initial [VOC]/ } \\
\text { ppbV }\end{array}$ & $\begin{array}{c}\text { Initial }[\mathrm{NO}] / \\
\mathrm{ppbV}\end{array}$ & $\begin{array}{c}\text { Initial }\left[\mathrm{NO}_{2}\right] / \\
\mathrm{ppbV}\end{array}$ & $\begin{array}{c}\mathrm{VOC} / \mathrm{NO}_{\mathrm{x}} \\
\text { Ratio }\end{array}$ & $\begin{array}{c}\text { Relative } \\
\text { humidity/ } \\
\%\end{array}$ & $\begin{array}{l}\text { Exp. } \\
\text { duration } 1 / \\
\text { mins. }\end{array}$ & $\begin{array}{c}\text { Peak }[\mathrm{OH}]^{2} / \\
\text { pptV }\end{array}$ & $\begin{array}{c}\text { Average } \\
{[\mathrm{OH}]^{2} /} \\
\mathrm{pptV}\end{array}$ & $\begin{array}{c}\text { CIR-MS } \\
\text { conditions } 3 \\
(E / N) / \mathrm{Td}\end{array}$ \\
\hline 1 & 560 & 129 & 141 & 2.07 & 52 & 539 & 0.06 & 0.04 & $120 / 170$ \\
\hline 2 & 1180 & 535 & 0 & 2.21 & 49 & 521 & 0.04 & 0.02 & $120 / 170$ \\
\hline 3 & 143 & 134 & 129 & 0.54 & 48 & 596 & 0.08 & 0.06 & $140 / 140$ \\
\hline 4 & 554 & 135 & 129 & 2.10 & 52 & 521 & 0.04 & 0.02 & $120 / 150$ \\
\hline 5 & 151 & \multicolumn{2}{|c|}{ Continuous HONO input ${ }^{4}$} & $\sim 15.10$ & 62 & 488 & 0.06 & 0.05 & $90 / 150$ \\
\hline 6 & 597 & 135 & 130 & 2.25 & 53 & 462 & 0.04 & 0.03 & $90 / 190$ \\
\hline 7 & 166 & Continuous & HONO input ${ }^{4}$ & $\sim 16.60$ & 50 & 549 & 0.08 & 0.06 & $90 / 190$ \\
\hline
\end{tabular}

${ }^{1}$ Experiment duration taken from the time that chamber lights were switched on

2 Estimated peak and experiment average $[\mathrm{OH}]$ inferred from TMB measurement

${ }^{3} \mathrm{E} / \mathrm{N}$ conditions of the centre reaction cell/ECC ramping region

${ }^{4}$ HONO injected continuously throughout experiment, chamber concentration $\sim 10 \mathrm{ppbV}$

spectrometer equipped with a wide bore reflectron array. In the current study proton transfer was used as the means of ionization and the proton donor was the hydronium ion $\left(\mathrm{H}_{3} \mathrm{O}^{+}\right)$(Lindinger et al., 1993). In order to generate the primary reagent ions, water vapour was delivered to the ion source by bubbling a high purity nitrogen carrier gas (Air Liquid, Ch, grade 7.0) through a glass vessel containing ultra-pure deionized water $(15 \mathrm{M} \Omega)$ at a rate of $30-52 \mathrm{sccm}$. Sample air from the PSI aerosol chamber was delivered to the CIR-TOF-MS at a rate of 200-275 sccm via an insulated $2 \mathrm{~m}$ long Teflon line and a PTFE critical orifice. Both the sample line and critical orifice were heated to $40^{\circ} \mathrm{C}\left( \pm 1^{\circ} \mathrm{C}\right)$ in order to limit wall losses. For brief intervals during certain experiments a particle filter was placed in the sample line to verify that all measured signals were due to gas phase species. The combined reagent and sample gas flows led to drift cell operating pressures in the range 6-9 mbar. A positive potential difference was applied across the drift cell to guide the ions into the mass spectrometer. The drift cell electric field (and therefore internal energy) was varied for certain experiments in order to enhance sensitivity to certain VOCs (see Table 1). The potential difference between the final two electrodes of the cell was varied to facilitate collision-induced dissociation of the ionised sample and hence to allow controlled removal of unwanted water cluster ions, i.e. $\mathrm{MH}^{+} .\left(\mathrm{H}_{2} \mathrm{O}\right)_{n}$ (where $\mathrm{M}$ represents the target VOC and $n$ is $\geq 1$ ). The experiment specific drift cell $E / N$ ratios (where $E$ is the electric field and $N$ is the gas number density) are provided in Table 1.

As stated earlier, an important feature of time-offlight mass spectrometry is the ability to achieve a much higher mass resolution than alternative techniques, notably quadrupole mass spectrometry. The mass resolution attained in the current study was in the region of $0.01 \mathrm{Da}$, which has proved useful in confirming the assignment of several high mass peaks.
The sum of hydro and organic peroxy radicals (i.e. $\left.\sum\left(\mathrm{HO}_{2}+\Sigma_{i} \mathrm{R}_{i} \mathrm{O}_{2}\right)\right)$ present in the chamber was also measured during low $\mathrm{NO}_{\mathrm{x}}$ experiments using a dual channel Peroxy Radical Chemical Amplifier (PERCA). The PERCA deployed during this work was similar to that described in Green et al. (2006), but with inlet systems as per Monks et al. (1998).

\subsection{Calibration}

A wide array of compounds was detected using the CIRTOF-MS and it was therefore impractical to carry out independent calibrations for all measured species. Consequently, where no calibration standard was available for a given compound the calibration factor determined for a structurally similar surrogate was utilised (see supplementary material http://www.atmos-chem-phys.net/9/635/2009/ acp-9-635-2009-supplement.pdf, Table A1). If no appropriate surrogate could be found, measurements are reported in terms of instrument signal (i.e. normalised ion counts per second (ncps) see Sect. 3.7). VOC yields quoted in the following discussion therefore act only as a guide for those compounds where surrogates have been employed. Table A1 provides comprehensive details of all VOC calibrations employed in the current study. Considering all instrument and calibration associated uncertainties (Wyche et al., 2007), the overall CIR-TOF-MS measurement errors lay within the range 2.9-27.6\% (see Table A1).

Owing to experimental time constraints, a PERCA chain length calibration was not carried out following all experiments. Consequently, a typical chain length of 109 (obtained from previous experiments (Parker, 2007)) was assumed to provide reasonable estimates of the peroxy radical concentrations. The amplification chain length of the PERCA varies between $\sim 80$ and 150 . When combined with instrument 


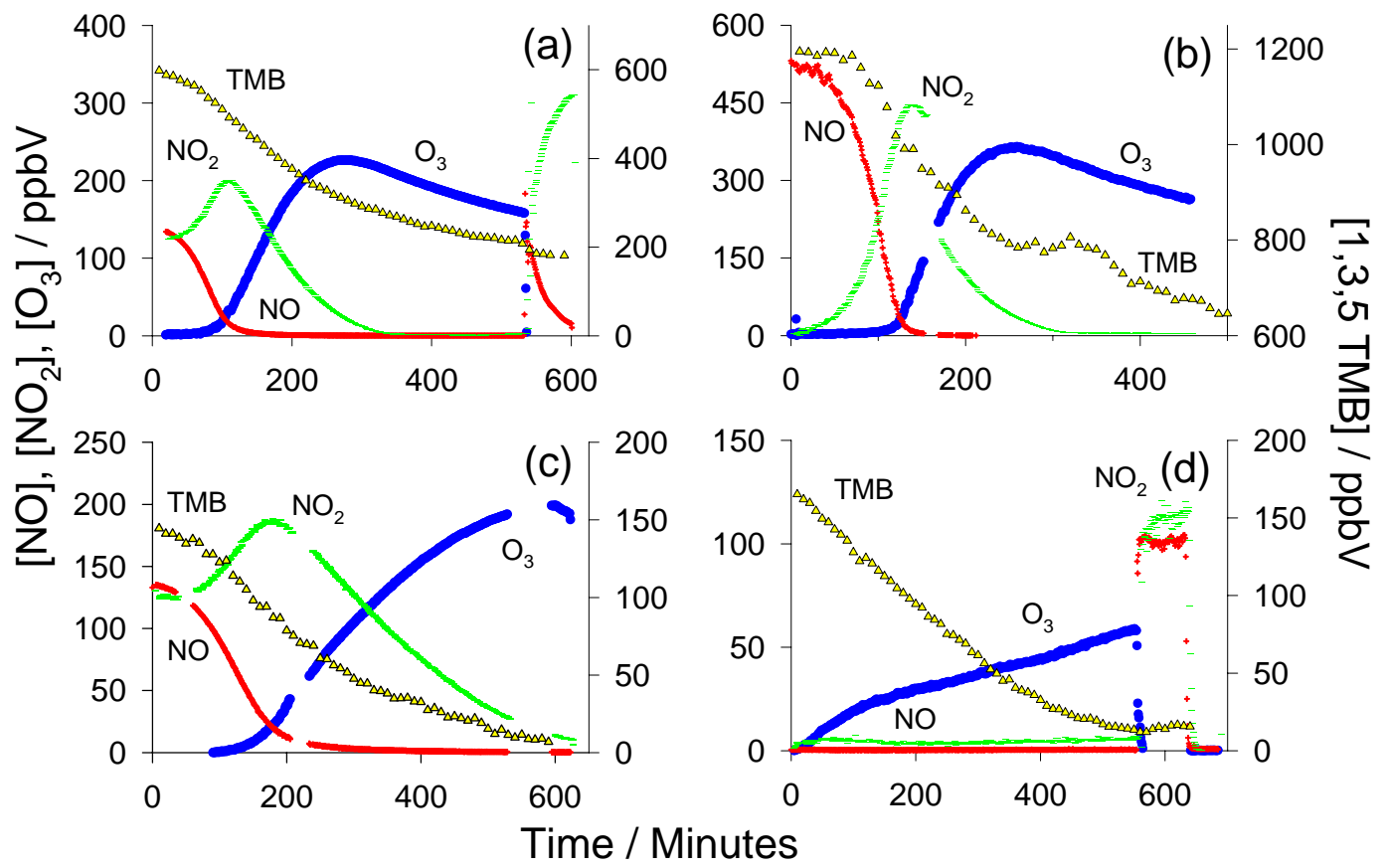

Fig. 1. Temporal evolution of the major gas phase components of the 1,3,5-TMB photooxidation system during (a) experiment 6 (VOC/NO $/ 2: 1$ ), (b) experiment 2 (VOC/NO $\sim 2: 1$, NO only), (c) experiment $3\left(\mathrm{VOC}_{\mathrm{x}} \sim \mathrm{NO}_{\mathrm{x}} \sim 1: 2\right)$ and $(\mathbf{d})$ experiment $7\left(\mathrm{VOC} / \mathrm{NO}_{\mathrm{x}} \sim 17: 1\right.$ ). In each plot the left ordinate axis gives the concentration of the inorganic components $\left(\mathrm{NO}, \mathrm{NO}_{2}\right.$ and $\left.\mathrm{O}_{3}\right)$ while the right axis gives the concentration of TMB. For (a) and (d) the chamber lights were switched off for the "dark phase" at 460 and 550 min, respectively, followed by NO injection (see text for details).

uncertainties this gives an estimated peroxy radical uncertainty of $42 \%$ (Fleming et al., 2006a, 2006b).

\section{Results and discussion}

The chamber conditions in this work can be broadly divided into two groups, high $\mathrm{NO}_{\mathrm{x}}$ and low $\mathrm{NO}_{\mathrm{x}}$. In the high $\mathrm{NO}_{\mathrm{x}}$ experiments the initial $\mathrm{NO}_{\mathrm{x}}$ concentration was $>250 \mathrm{ppbV}$, whereas low $\mathrm{NO}_{\mathrm{x}}$ conditions corresponded to $\mathrm{NO}_{\mathrm{x}}$ at $\leq 5 \mathrm{ppbV}$. The results from the high and low $\mathrm{NO}_{\mathrm{x}}$ experiments are reported separately in the following sections. Comparisons of gas and aerosol phase measurements carried out under different $\mathrm{VOC} / \mathrm{NO}_{\mathrm{x}}$ regimes are utilised during the present study to help elucidate the underlying SOA formation mechanisms.

3.1 Chamber inorganic species and the SOA precursor under high $\mathrm{NO}_{\mathrm{x}}$ conditions

Figure 1a-d displays the temporal evolution of the major inorganic gas phase components of the chamber system and the 1,3,5-trimethylbenzene precursor in several different experiments (listed in Table 1). In all instances the experiment start time is taken from the point at which chamber lights were switched on and hence the photochemistry initiated. On average the duration of each experiment was of the order of $8-10 \mathrm{~h}$.

The majority of experiments (experiments 1-4 and 6; see Table 1) were carried out under high $\mathrm{NO}_{\mathrm{x}}$ conditions. During these experiments the initial $\mathrm{VOC} / \mathrm{NO}_{\mathrm{x}}$ ratio was varied between 0.54 and 2.25. Figure 1a summarises the findings for experiment 6 . Experiment 6 constitutes a typical example of a high $\mathrm{NO}_{\mathrm{x}}$ experiment with $\mathrm{VOC} / \mathrm{NO}_{\mathrm{x}} \sim 2: 1$; hence it is used as focus for discussion. The experiment essentially begins with the production of ground state atomic oxygen, which originates from the photolysis of $\mathrm{NO}_{2}$. This results in the subsequent production of ozone, photolysis of which in the presence of water, yields $\mathrm{OH}$. $\mathrm{OH}$ can also be generated in smog chambers from HONO photolysis. HONO is generally produced in all such systems following wall reactions involving $\mathrm{NO}_{2}$ (e.g. Metzger et al., 2008a). Following its production, $\mathrm{OH}$ reacts readily with TMB to generate a complex array of oxidation products, including organic peroxy radicals $\left(\mathrm{RO}_{2}\right)$, hydroperoxy radicals $\left(\mathrm{HO}_{2}\right)$ and oxygenated and nitrated VOCs (Calvert et al., 2002).

The oxidation profiles for TMB during all high $\mathrm{NO}_{\mathrm{x}}$ experiments exhibited similar behaviour, with a short initial concentration plateau corresponding to the time required to initiate the $\mathrm{OH}$ chemistry, followed by a peak in oxidation rate $\sim 160$ min after lights on. After this period, the TMB concentration profile was characterised by a roughly constant 
decay. For each high $\mathrm{NO}_{\mathrm{x}}$ experiment a plot of $\ln [\mathrm{TMB}]$ vs. time is approximately linear, with no distinct change in rate with accumulation of ozone. This result verifies that as expected 1,3,5-TMB does not react appreciably with $\mathrm{O}_{3}$. Consequently, with $\mathrm{NO}_{3}$ oxidation of TMB negligible under the experimental chamber conditions employed, the major chemical loss of TMB would have resulted solely from its reaction with $\mathrm{OH}$. An estimation of $[\mathrm{OH}]$ can therefore be inferred from the rate of decay of TMB recorded by CIR-TOF-MS. For experiments with an initial VOC/NO ${ }_{x}$ ratio of $\sim 2: 1$, peak $\mathrm{OH}$ concentrations were $\sim 0.04 \mathrm{pptV}$ and experiment average concentrations were $\sim 0.03 \mathrm{pptV}$ (using $k_{\mathrm{OH}+1,3,5 T M B}=(5.67 \pm 1.13) \times 10^{-11} \mathrm{~cm}^{3}$ molecules ${ }^{-1} \mathrm{~s}^{-1}$ at $T=298 \mathrm{~K}$; Calvert et al., 2002).

With the production of both $\mathrm{HO}_{2}$ and $\mathrm{RO}_{2}$ radicals, $\mathrm{NO}$ became oxidised to $\mathrm{NO}_{2}$, leading to the concentration peak seen in Fig. 1a-c. Due to the presence of the VOC (and hence $\mathrm{RO}_{2}$ ), the $\mathrm{NO} / \mathrm{NO}_{2}$ partitioning was such that there was a positive deviation from the photostationary state resulting in net initial ozone production (Monks, 2005). As noted in other chamber studies (e.g. Bloss et al., 2005a; Dommen et al., 2006), the peak in $\left[\mathrm{NO}_{2}\right]$ and the initial accumulation of $\mathrm{O}_{3}$ roughly coincide with the observed maximum rate of loss of the VOC and the peak in $[\mathrm{OH}]$. Eventually, $\mathrm{NO}_{2}$ was removed from the gas phase through the production of nitric acid $\left(\mathrm{HNO}_{3}\right)$, reactions on the chamber walls and incorporation into organic nitrates and the aerosol phase (Monks, 2005). As $\mathrm{NO}_{2}$ chemistry constitutes the sole route to $\mathrm{O}_{3}$ formation within the chamber, the removal of $\mathrm{NO}_{\mathrm{x}}$ from the system was followed by a fall in the concentration of $\mathrm{O}_{3}$. At the conclusion of experiment $6, \sim 70 \%$ of the VOC precursor had been consumed and the concentrations of $\mathrm{NO}$ and $\mathrm{NO}_{2}$ had fallen to negligible levels (Fig. 1a).

In order to evaluate the chemical mechanisms underlying the TMB photooxidation system, at the conclusion of certain experiments the chamber lights were switched off and the total chamber ozone was titrated from the system with the addition of excess NO to the gas phase matrix. The effect of this "dark phase" on the VOC chemistry will be discussed below in Sect. 3.9, however, it should be noted at this point that the $\mathrm{NO}$ addition, $\mathrm{O}_{3}$ titration and resultant $\mathrm{NO}_{2}$ production can be seen in Fig. 1a and d for experiments 6 and 7 (high and low $\mathrm{NO}_{\mathrm{x}}$, respectively).

For experiment $2\left(\mathrm{VOC} / \mathrm{NO}_{\mathrm{x}} \sim 2: 1\right)$ shown in Fig. 1b, initial $\mathrm{NO}_{\mathrm{x}}$ was introduced solely in the form of $\mathrm{NO}$ and starting concentrations were set to two times those of other high $\mathrm{NO}_{\mathrm{x}}$ experiments with $\mathrm{VOC} / \mathrm{NO}_{\mathrm{x}} \sim 2: 1$. To initiate the oxidation process in this instance, $\mathrm{HONO}$ and $\mathrm{NO}_{2}$ had first to be liberated from the illuminated chamber walls following known heterogeneous chemical mechanisms (Stroud et al., 2004; Metzger et al., 2008a).

Experiment 3 involved a reversal of the $\mathrm{VOC} / \mathrm{NO}_{x}$ ratio to a value of roughly $1: 2$, but still with high starting concentrations. As can be seen in Fig. 1c the $\mathrm{NO}_{\mathrm{x}}, \mathrm{O}_{3}$ and TMB components of the system exhibited similar profiles to those observed during the other high $\mathrm{NO}_{\mathrm{x}}$ experiments, but with a number of key exceptions. When the $\mathrm{VOC} / \mathrm{NO}_{\mathrm{x}}$ ratio was decreased to $\sim 0.5$, the rate of decay of TMB appeared enhanced, suggesting higher levels of oxidant. In this instance inferred $\mathrm{OH}$ radical levels were on average $\sim 0.06 \mathrm{ppt} \mathrm{V}$ (peak $\sim 0.08 \mathrm{pptV}$ ), i.e. twice as high as levels observed in the other high $\mathrm{NO}_{\mathrm{x}}$ experiments. This finding is most likely a result of balancing of the $\mathrm{OH} / \mathrm{HO}_{2}$ ratio in the hydroxyl radical cycle, where a relatively higher proportion of $\mathrm{NO}$ (with respect to that of the VOC) will force a shift towards $\mathrm{OH}$ in the chamber $\mathrm{HO}_{\mathrm{x}}$ balance. The impact of an elevated $\mathrm{OH}$ density is reflected in the amount of VOC consumed by the conclusion of the experiment, i.e. after 600 min less than $10 \%$ of the initial TMB remained. In addition to this, a lower $\mathrm{RO}_{2} / \mathrm{NO}_{\mathrm{x}}$ ratio will slow the cycling of $\mathrm{NO}$ to $\mathrm{NO}_{2}$ and hence delay subsequent $\mathrm{O}_{3}$ production. This effect can be seen in the data presented in Fig. 1c, where a significant delay is evident in the times at which $\mathrm{NO}_{2}$ and $\mathrm{O}_{3}$ reached their respective peaks, and at which NO reached negligible concentrations (when compared to experiments with $\mathrm{VOC} / \mathrm{NO}_{\mathrm{x}} \sim 2: 1$ ).

3.2 Chamber inorganic species and the SOA precursor under low $\mathrm{NO}_{\mathrm{x}}$ conditions

The second component of the chamber study comprised two low $\mathrm{NO}_{\mathrm{x}}$ experiments, experiments 5 and 7 , during which $\left[\mathrm{NO}_{\mathrm{x}}\right]$ was kept below $\sim 5 \mathrm{ppbV}$. In the case of experiment $7, \mathrm{SO}_{2}$ gas was added to the chamber in order to generate sulfuric acid $\left(\mathrm{H}_{2} \mathrm{SO}_{4}\right)$ seed particles.

As discussed in Sect. 2.2, during the low $\mathrm{NO}_{\mathrm{x}}$ experiments the chamber was supplied with a continuous source of NO (from HONO) at a rate greater than the sum of its removal pathways. Consequently, the chamber remained in a state of net ozone production throughout the experiment and therefore no distinct peak and fall was observed in the ozone concentration profile (see Fig. 1d).

In addition to supplying the chamber with NO, HONO photolysis constituted an additional source of $\mathrm{OH}$. The photolysis rate of nitrous acid (j(HONO)) for the PSI chamber has been measured as $2.7 \times 10^{-4} \mathrm{~s}^{-1}$, which yields an $\mathrm{OH}$ production rate $(\mathrm{P}(\mathrm{OH}))$ of $2.7 \mathrm{pptV} \mathrm{s}^{-1}$ for a constant HONO value of $10 \mathrm{ppbV}$. As $\mathrm{P}(\mathrm{OH})$ from the photolysis of HONO was several times larger than $\mathrm{P}(\mathrm{OH})$ from ozone at any instant during the low $\mathrm{NO}_{\mathrm{x}}$ experiments, the level of $\mathrm{OH}$ in the chamber was roughly constant. Evidence for this can be seen in Fig. 1d, where the rate of decay of TMB during experiment 7 remained roughly constant during the majority of the experiment. Using the rate of oxidation of TMB (as described in Sect. 3.1), the average $\mathrm{OH}$ concentrations in the chamber for the two low $\mathrm{NO}_{\mathrm{x}}$ experiments 5 and 7 were estimated to be $\sim 0.05$ and $0.06 \mathrm{pptV}$.

Tables 1, 2 and 3 lists key measured parameters describing the evolution of the inorganic species for each experiment. 
Table 2. Summary of the aerosol-pahse parameters for experiments 1-7.

\begin{tabular}{|c|c|c|c|c|c|c|c|c|c|c|}
\hline $\begin{array}{l}\text { Exp. } \\
\text { No. }\end{array}$ & $\begin{array}{c}\text { CPC } \\
\text { nuc. } \mathrm{T}^{1 /} \\
\text { mins. }\end{array}$ & $\begin{array}{c}\text { SMPS } \\
\text { nuc. } \mathrm{T}^{2} / \\
\text { mins. }\end{array}$ & $\begin{array}{l}\text { Half max. } \\
\text { [No.] } \mathrm{T}^{3} / \\
\text { mins. }\end{array}$ & $\begin{array}{c}\text { Max. } \\
\text { [No.] } \mathrm{T}^{3} / \\
\text { mins. }\end{array}$ & $\begin{array}{c}\text { Max. [No.] }]^{3 /} \\
\# \mathrm{~cm}-3\end{array}$ & $\begin{array}{c}\text { [NO]@ } \\
\text { nucleation/ } \\
\text { ppbV }\end{array}$ & $\begin{array}{c}{[\mathrm{NO}] \rightarrow 0} \\
\text { time }^{4} / \\
\text { mins. }\end{array}$ & $\begin{array}{c}\text { Aerosol } \\
\text { diameter } \\
\text { (time)/ } \\
\text { nm (mins.) }\end{array}$ & $\begin{array}{l}\text { Aerosol mass } \\
\text { (time)/ } \\
\mu \mathrm{g} \mathrm{m}^{-3} \\
\text { (mins.) }\end{array}$ & $\begin{array}{c}\text { SOA } \\
\text { Yield/ } \\
\%\end{array}$ \\
\hline 1 & 108 & 108 & 183 & 225 & 580 & 16.2 & 152 & 387 (357) & 47 (465) & 1.94 \\
\hline 2 & 145 & 149 & 167 & 228 & 1099 & 6.2 & $152-169^{5}$ & $663(505)$ & $182(433)$ & 7.47 \\
\hline 3 & 400 & 420 & 543 & 609 & 406 & 1.4 & 325 & $155(618)$ & $2(621)$ & 0.29 \\
\hline 4 & 188 & 193 & 226 & 256 & 491 & 1.2 & 157 & 507 (484) & $36(415)$ & 2.29 \\
\hline 5 & 50 & 58 & 94 & 163 & 407 & 0.4 & $6_{-}$ & $462(513)$ & $38(502)$ & 6.36 \\
\hline 6 & 184 & 182 & 218 & 257 & 494 & 1.4 & 162 & 484 (487) & $31(358)$ & 1.79 \\
\hline 7 & 22 & 28 & 43 & 76 & 2216 & 0.4 & $6_{-}$ & $404(550)$ & 45 (487) & 6.21 \\
\hline
\end{tabular}

${ }^{1}$ Nucleation time obtained using data from CPC (particles of diameter $\geq 3 \mathrm{~nm}$ )

2 Nucleation time obtained using data from SMPS (particles of diameter $\geq 15 \mathrm{~nm}$ )

${ }^{3}$ Data obtained from SMPS

${ }^{4}$ Defined as the time at which [NO] reaches $2 \mathrm{ppbV}$

${ }^{5} \mathrm{NO}$ analyser off line, [NO] dropped below $2 \mathrm{ppbV}$ during this time

${ }^{6}$ Low $\mathrm{NO}_{\mathrm{x}}$ experiment, [NO] $<1 \mathrm{ppbV}$ throughout experiment

Table 3. Quantity of organic precursor consumed and peak inorganic concentrations.

\begin{tabular}{lcccccc}
\hline $\begin{array}{l}\text { Exp. } \\
\text { No. }\end{array}$ & $\begin{array}{c}\text { TMB } \\
\text { consumed/ } \\
\%\end{array}$ & $\begin{array}{c}\text { Peak } \\
\text { dTMB]/dt/ } \\
\text { mins. }\end{array}$ & $\begin{array}{c}\text { Peak }\left[\mathrm{O}_{3}\right] \\
\text { time/ } \\
\text { mins. }\end{array}$ & $\begin{array}{c}\text { Peak }\left[\mathrm{O}_{3}\right] / \\
\mathrm{ppbV}\end{array}$ & $\begin{array}{c}\text { Peak }\left[\mathrm{NO}_{2}\right] \\
\text { time/mins. }\end{array}$ & $\begin{array}{c}\text { Peak }\left[\mathrm{NO}_{2}\right] / \\
\mathrm{ppbV}\end{array}$ \\
\hline 1 & 89.4 & 130 & 278 & 274.1 & 103 & 212.7 \\
2 & 44.3 & 120 & 259 & 365.2 & 137 & 446.2 \\
3 & 91.5 & 120 & 600 & 199.1 & 188 & 187.4 \\
4 & 63.5 & 110 & 287 & 230.8 & 104 & 196.4 \\
5 & 82.2 & - & 489 & 43.8 & - & - \\
6 & 62.1 & 110 & 284 & 226.3 & 110 & 200.9 \\
7 & 92.5 & - & 551 & 58.9 & - & - \\
\hline
\end{tabular}

\subsection{Chamber aerosol formation under high $\mathrm{NO}_{\mathrm{x}}$ conditions}

Figure $2 \mathrm{a}-\mathrm{d}$ summarises the key aerosol phase parameters for the four variants of the TMB photooxidation study, i.e. the total aerosol number density, total aerosol volume and mean geometric particle diameter.

For experiments 1-6 no seeding was employed in the simulation chamber and hence new aerosol formation occurred via homogeneous nucleation involving certain key semi-and non-volatile oxidation products of the precursor VOC (Seinfeld and Pankow, 2003; Holmes, 2007). The nucleation event observed during experiment 6 (high $\mathrm{NO}_{\mathrm{x}}$ experiment, VOC/NO $/ 2: 1$ ) is clearly evident in Fig. 2a, seen as a dramatic increase in the total number density of particles in the chamber at $\sim 185 \mathrm{~min}$. In this study we define nucleation to have occurred once the differential of the particle number density (with respect to time) exceeds a value of one for three consecutive measurements (i.e. when the particle count tends away from the baseline). Nucleation times are given for the CPC and the SMPS instruments in Table 1. However, as the CPC measures particles closer in size to the nucleating cluster (i.e. $\sim 1.5 \mathrm{~nm}$ ), it is the CPC derived nucleation times and number densities that are employed during the following analysis and discussion.

In experiment 6 new SOA formation continued for approximately $100 \mathrm{~min}$, by which time a maximum number density of $\sim 490$ particles $\mathrm{cm}^{-3}$ was reached (in the size range 15$690 \mathrm{~nm}$ ). During this time, via condensation and then coagulation mechanisms, the particles grew in size to a maximum mean diameter of $\sim 480 \mathrm{~nm}$ at $\sim 490 \mathrm{~min}$. The total volume of chamber SOA followed a similar trend to that of particle diameter. Ultimately the number density of SOA particles and the total suspended chamber mass decreased owing to coagulation and deposition to the chamber walls. Table 2 highlights the reproducibility of aerosol phase parameters between repeat studies of the three high $\mathrm{NO}_{\mathrm{x}}$ experiments carried out at $\mathrm{VOC} / \mathrm{NO}_{\mathrm{x}} \sim 2: 1$ (experiments 1, 4 and 6). 


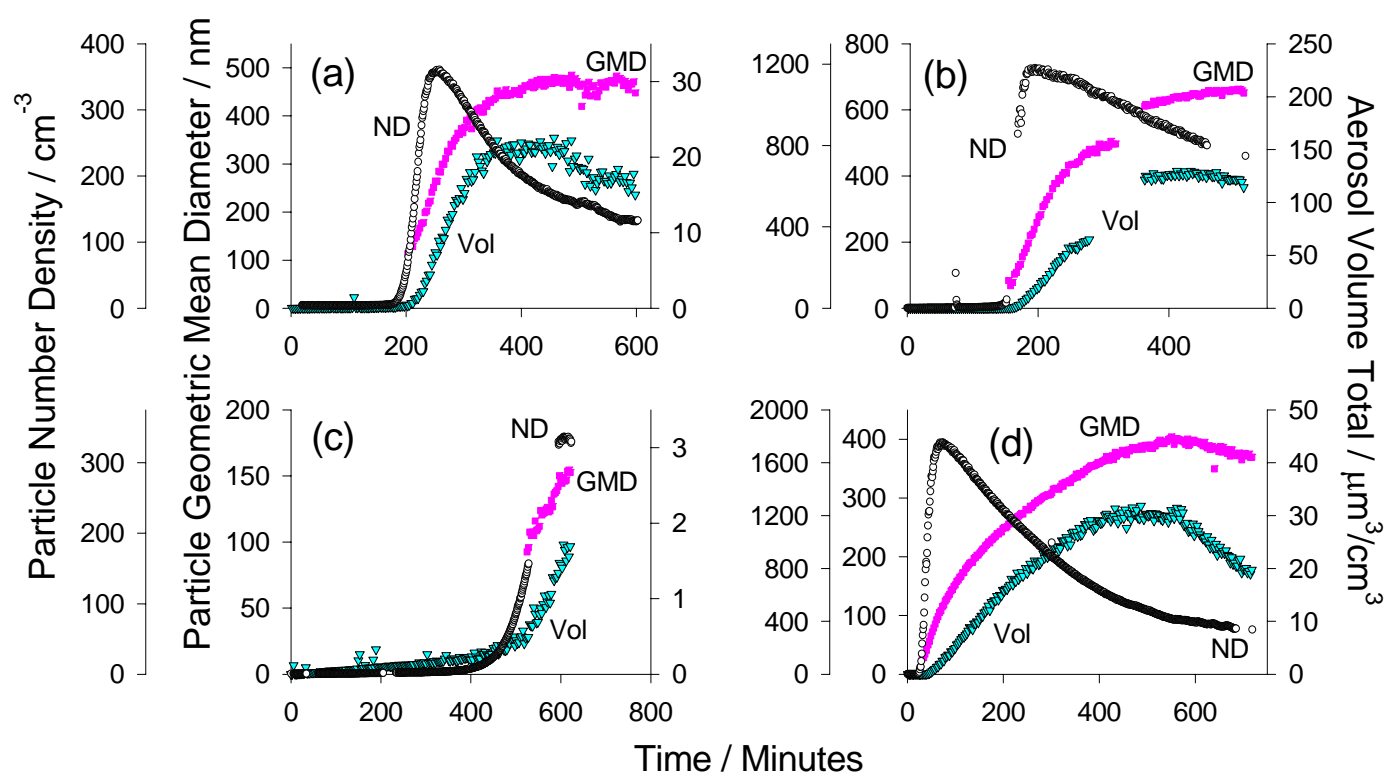

Fig. 2. Temporal evolution of the aerosol number density (ND), geometric mean diameter (GMD) and volume concentration (Vol) within the chamber during (a) experiment $6\left(\mathrm{VOC} / \mathrm{NO}_{\mathrm{x}} \sim 2: 1\right)$, (b) experiment $2\left(\mathrm{VOC} / \mathrm{NO}_{\mathrm{x}} \sim 2: 1, \mathrm{NO}\right.$ only), (c) experiment $3\left(\mathrm{VOC} / \mathrm{NO}_{\mathrm{x}} \sim 1: 2\right)$ and $(\mathbf{d})$ experiment 7 ( $\left.\mathrm{VOC} / \mathrm{NO}_{\mathrm{x}} \sim 17: 1\right)$. For (a) and (d) the chamber lights were switched off for the "dark phase" at 460 and 550 min, respectively, followed by NO injection (see text for details).

Following the analysis performed by Baltensperger and colleagues (Baltensperger et al., 2005), total SOA mass has been determined from the measured SOA volume by assuming a density of $1.4 \mathrm{~g} \mathrm{~cm}^{-3}$. In the case of experiment 6 , a maximum SOA mass of approximately $31 \mu \mathrm{g} \mathrm{m}^{-3}$ was reached. As no wall loss corrections have been applied to the aerosol phase data, this value constitutes a lower limit and should be treated with care. Consequently, a "relative" SOA yield (Y) was calculated according to Eq. (1) (after Odum et al., 1996):

$\mathrm{Y}=\frac{\mathrm{M}_{0}}{\Delta \mathrm{VOC}} \times 100$

In the above expression $\mathrm{M}_{0}$ corresponds to the peak mass of SOA produced and $\triangle \mathrm{VOC}$ is the amount of the precursor VOC consumed at the peak SOA mass (both expressed in units of $\mu \mathrm{g} \mathrm{m}^{-3}$ ). Note, the yields presented have a level of uncertainty associated with them owing to the use of nonwall loss corrected SOA mass. Yields for the three repeat experiments with a $\mathrm{VOC} / \mathrm{NO}_{\mathrm{x}}$ ratio $\sim 2: 1$ (i.e. experiments 1 , 4 and 6) were 1.9, 2.3 and $1.8 \%$, respectively.

The temporal behaviour of the measured aerosol parameters for experiment $2\left(\mathrm{VOC} / \mathrm{NO}_{\mathrm{x}} \sim 2: 1, \mathrm{NO}\right.$ only) was similar to those of experiments 1,4 and 6 . However, as the initial concentration of both TMB and NO was set to twice that of the other high $\mathrm{NO}_{\mathrm{x}}\left(\mathrm{VOC} / \mathrm{NO}_{\mathrm{x}} \sim 2: 1\right)$ experiments, an approximate two-fold increase in the maximum number density of particles was observed $\left(\sim 1100\right.$ particles $\mathrm{cm}^{-3}$ in the size range $15-690 \mathrm{~nm}$ ). Also, particles grew to larger maximum mean diameters $(\sim 660 \mathrm{~nm})$ and the ultimate experiment SOA yield was roughly four times greater than that of the other high $\mathrm{NO}_{\mathrm{x}}$ experiments (1, 4 and 6), at approximately $7.5 \%$. The findings described here for an enhanced level of starting material are consistent with those previously reported (e.g. Paulsen et al., 2005; Gross et al., 2006).

When the starting $\mathrm{VOC} / \mathrm{NO}_{\mathrm{x}}$ ratio was reversed to $\sim 1: 2$ for experiment 3, SOA formation was significantly delayed, with nucleation occurring around $215 \mathrm{~min}$ later than in experiment 6 . By the conclusion of experiment $3(\sim 600 \mathrm{~min})$ the chamber aerosol appeared to still be in a state of growth; no distinct peak in either size or mass had been reached, however, the SOA number density had reached its maximum (see Fig. 2c). Consequently, a relative SOA yield can only be approximated in this instance by taking the aerosol mass produced at the conclusion of the experiment. Although this yield value is not necessarily fully quantitative, it serves as a guide to indicate the level of SOA formed under the conditions of experiment 3 . With a $\mathrm{VOC} / \mathrm{NO}_{\mathrm{x}}$ ratio of $\sim 1: 2$, an approximate SOA yield of $0.3 \%$ was achieved, i.e. roughly an order of magnitude lower than for the larger $\mathrm{VOC} / \mathrm{NO}_{\mathrm{x}}$ ratios. With more than $90 \%$ of the precursor VOC consumed by termination of the experiment and with primary and secondary oxidation products having reached their concentration peaks, it may be assumed that further aerosol growth after this point would be minimal.

From the above discussion and from inspection of Table 2 it is clear that for each experiment conducted under high $\mathrm{NO}_{x}$ conditions a significant delay or "incubation" period 
was witnessed before the nucleation event. For experiments 1, 2, 4 and $6\left(\mathrm{VOC} / \mathrm{NO}_{\mathrm{x}} \sim 2: 1\right)$ this period lasted for approximately $110,145,190$ and $185 \mathrm{~min}$, respectively, and for experiment $3\left(\mathrm{VOC} / \mathrm{NO}_{\mathrm{x}} \sim 1: 2\right)$ was over twice as long at $400 \mathrm{~min}$. Evidence for this incubation period has been reported for several other aromatic oxidation systems, including benzene, toluene, $o$-xylene and $m$-xylene in a number of different simulation chambers (Izumi et al., 1988; Johnson et al., 2004, 2005; Song et al., 2005; Ng et al., 2007).

It has been proposed that the existence and duration of the incubation period is directly related to the presence of $\mathrm{NO}$ in the gas phase (Johnson et al., 2004, 2005). Results obtained by Johnson et al. (2005) from a gas phase oxidation model coupled to an absorptive aerosol transfer scheme showed that the less volatile organic hydroperoxides, formed from the self-reactions of hydro and organic peroxy radical species (R3 and R4), were significant contributors to SOA mass. Consequently, new particle formation and growth would be closely linked to the ambient levels of $\mathrm{NO}$, which may preferentially react with $\mathrm{HO}_{2}$ and $\mathrm{RO}_{2}$ via reactions (R1) and (R2) in the scheme below, limiting the capacity of the system to form peroxides:

$$
\begin{aligned}
\mathrm{NO}+\mathrm{HO}_{2} & \rightarrow \mathrm{NO}_{2}+\mathrm{OH} \\
\mathrm{NO}+\mathrm{RO}_{2} & \rightarrow \mathrm{NO}_{2}+\mathrm{RO} \\
& \rightarrow \mathrm{RONO}_{2} \\
\mathrm{RO}_{2}+\mathrm{RO}_{2} & \rightarrow \text { Products } \\
\mathrm{RO}_{2}+\mathrm{HO}_{2} & \rightarrow \text { ROOH }+\mathrm{O}_{2}
\end{aligned}
$$

The $\mathrm{RO}_{2}+\mathrm{RO}_{2}$ self-reaction ( $\mathrm{R} 3$ ) will proceed via one of three different pathways, the relative importance of which depends on the structure of the reacting $\mathrm{RO}_{2}$ radicals. Generally, the $\mathrm{RO}_{2}+\mathrm{RO}_{2}$ reaction will produce either (i) an equivalent alkoxy radical pair (RO), (ii) a carbonyl compound and an alcohol, or (iii) an organic peroxide (ROOR). Although reaction (R3) can lead to the formation of low volatility ROOR compounds, it proceeds at a considerably slower rate than reaction (R4), hence $\mathrm{ROOH}$ species may be of greater importance in SOA formation.

Johnson et al. (2005) proposed that once in the aerosol phase, the organic peroxides are able to take part in heterogeneous chemistry with certain aldehyde compounds to form peroxyhemiacetals. This thesis supports results from previous studies of various workers demonstrating the importance of heterogeneous chemistry in the aerosol, and in particular acetal and hemiacetal reactions involving carbonyl oxidation products (Jang and Kamens, 2001; Jang et al., 2003).

Following the methods detailed by $\mathrm{Ng}$ et al. (2007), an examination of the kinetics involved in reactions (R2)-(R4) enables us to infer the influence of the NO concentration on gas phase organic hydroperoxide formation during the current experiments. Equation (2) below accounts for reactions
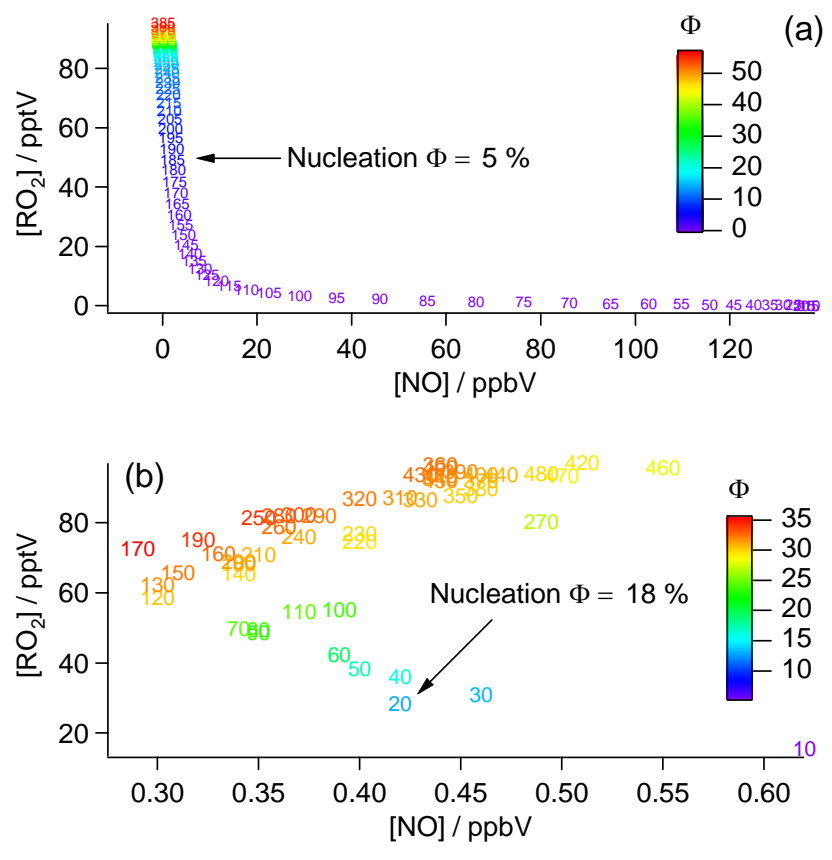

Fig. 3. Theoretical variation in partitioning of $\mathrm{RO}_{2}$ species with evolving chamber $[\mathrm{NO}]$ for (a) high $\mathrm{NO}_{\mathrm{x}}$ conditions and (b) low $\mathrm{NO}_{\mathrm{x}}$ conditions. $\Phi$ gives the percentage of $\mathrm{RO}_{2}$ species forming organic hydroperoxides (see Eq. (2) and text for further details). Graph number markers give the time after lights on.

(R2)-(R4) to determine the fraction of $\mathrm{RO}_{2}(\Phi)$ that forms hydroperoxides:

$\Phi=\frac{k_{4}\left[\mathrm{RO}_{2}\right][\mathrm{HO}]_{2}}{k_{4}\left[\mathrm{RO}_{2}\right]\left[\mathrm{HO}_{2}\right]+k_{3}\left[\mathrm{RO}_{2}\right]^{2}+k_{2}\left[\mathrm{RO}_{2}\right][\mathrm{NO}]}$

For this simple model the overall rate constant $k_{2}$ has been used to account for the fate of $\mathrm{RO}_{2}$ via reaction with $\mathrm{NO}$ by both reactions (R2a) and (R2b). Rate constants $k_{2}, k_{3}$ and $k_{4}$ taken from MCMv3.1, http://mcm.leeds.ac.uk/MCM.

Figure 3a shows the variation of $\Phi$ with NO concentration taken from experiment 6 , for a series of $\mathrm{HO}_{2}$ and $\mathrm{RO}_{2}$ concentrations generated from the chamber box model employed in a companion paper (Rickard et al., 2008). Figure 3 a clearly demonstrates that for the self-reaction route involving both hydro and organic peroxy radical species to become significant, either high radical levels are required (i.e. tens of $\mathrm{pptV}$ ) or the concentration of $\mathrm{NO}$ must approach zero. For $\Phi$ (hence hydroperoxide formation) to reach as much as $5 \%$ in this model, the concentration of $\mathrm{NO}$ must fall to $\sim 2 \mathrm{ppbV}$ (with $\sim 40$ and $50 \mathrm{pptV} \mathrm{HO}_{2}$ and $\mathrm{RO}_{2}$, respectively) and for $10 \%, \sim 1 \mathrm{ppbV}$ (with $\sim 50$ and $70 \mathrm{pptV} \mathrm{HO}_{2}$ and $\mathrm{RO}_{2}$, respectively). At the point of nucleation during experiment 6, Eq. (2) predicts $\Phi=5 \%$.

During experiments $1,2,4$ and $6\left(\mathrm{VOC} / \mathrm{NO}_{\mathrm{x}} \sim 2: 1\right)$, the time required for the NO concentration in the chamber to reach $2 \mathrm{ppbV}$ (i.e. to approach zero) ranged from $\sim 150$ to 


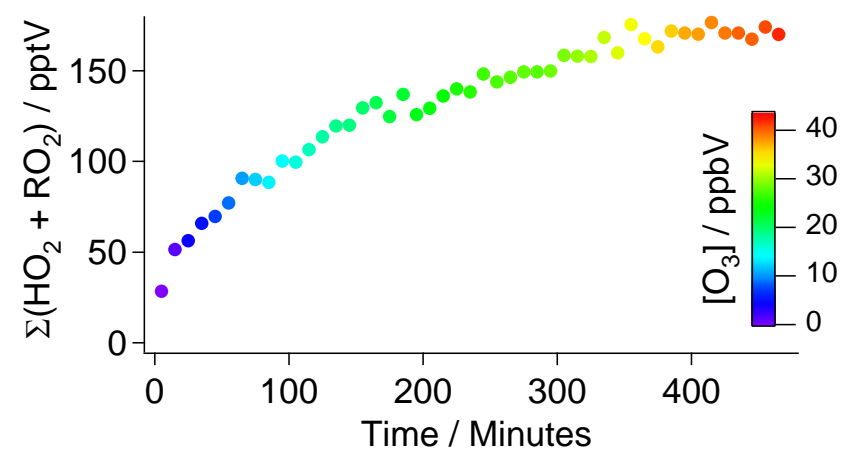

Fig. 4. Temporal evolution of the sum of hydro and organic peroxy radicals (i.e. $\left.\sum\left(\mathrm{HO}_{2}+\mathrm{RO}_{2}\right)\right)$ recorded by the PERCA during low $\mathrm{NO}_{\mathrm{X}}$ experiment $5\left(\mathrm{VOC} / \mathrm{NO}_{\mathrm{X}}\right.$ ratio $\left.\sim 15: 1\right)$.

$170 \mathrm{~min}$ (see Table 2). Contrasting these times with those of the nucleation event in each case, we see that SOA formation occurs only as [NO] drops towards zero, adding support to the thesis that peroxide chemistry is involved in SOA formation. However, during experiments 4 and 6 there is a further time delay (of $\sim 30$ and $20 \mathrm{~min}$, respectively) before particle formation occurs, implications of which are discussed in Sect. 3.5. The concentrations of NO at nucleation for the high $\mathrm{NO}_{\mathrm{x}}$ experiments 1, 2, 4 and 6 were 16.2, 6.2, 1.2, and $1.4 \mathrm{ppbV}$, respectively. Particle growth during experiment 1 was slower than other repeat experiments, an observation in line with the slightly higher [NO] at the point of SOA formation.

The hypothesis suggesting that the NO concentration in the chamber must reach a minimal value before nucleation can occur is supported by results obtained from varying the $\mathrm{VOC} / \mathrm{NO}_{\mathrm{x}}$ ratio. When the $\mathrm{VOC} / \mathrm{NO}_{\mathrm{x}}$ ratio was changed from 2:1 to $1: 2$ (experiment 3), a considerably longer time was required for the system chemistry to reduce the [NO] to negligible levels (see Table 2). Correspondingly, a delay was observed in the timing of the nucleation event. In addition to this, nucleation did not occur until approximately a further 75 min after [NO] had reached minimal levels.

\subsection{Chamber aerosol formation and peroxy radicals under} low $\mathrm{NO}_{\mathrm{x}}$ conditions

Figure 2 and Table 2 demonstrate the clear difference between the nucleation times of the high and low $\mathrm{NO}_{\mathrm{x}}$ experiments. During the low $\mathrm{NO}_{\mathrm{x}}$ experiments a distinctly shorter incubation period was observed before the onset of aerosol formation, i.e. $\sim 50$ and $20 \mathrm{~min}$ for experiments 5 and 7 , respectively, compared to an average of $\sim 155 \mathrm{~min}$ for the typical high $\mathrm{NO}_{\mathrm{x}}$ experiments (see Fig. 2d). During the low $\mathrm{NO}_{\mathrm{x}}$ (constant $\mathrm{HONO}$ ) experiments the concentration of $\mathrm{NO}$ up to the point of nucleation was no greater than $\sim 1 \mathrm{ppbV}$ and an additional radical source was present to supply $\mathrm{OH}$ and (therefore $\mathrm{HO}_{2}$ ) to the matrix. Consequently, it is highly likely that radical-radical self-reaction routes (R3 and R4) dominated the fate of the $\mathrm{RO}_{2}$ species from the start of the experiment. It should be noted that the length of the incubation period of each low $\mathrm{NO}_{\mathrm{x}}$ experiment (i.e. 5 and 7), is comparable to the length of the time delay between NO falling to negligible concentrations and nucleation during high $\mathrm{NO}_{\mathrm{x}}$ experiments 4 and 6.

The SOA yields obtained during low $\mathrm{NO}_{\mathrm{x}}$ experiments 5 and 7 were 6.4 and $6.2 \%$, respectively, i.e. roughly 3.5 and 22 times larger than those achieved under high $\mathrm{NO}_{\mathrm{x}}$ conditions of $\mathrm{VOC} / \mathrm{NO}_{\mathrm{x}} \sim 2: 1$ and 1:2, respectively. It should be noted that in the latter instance (experiment $3, \mathrm{VOC} / \mathrm{NO}_{\mathrm{x}} \sim 1: 2$ ), the experiment was conducted with the same initial TMB concentration as the low $\mathrm{NO}_{\mathrm{x}}$ experiments, and thus it is unlikely that enhanced yields under low $\mathrm{NO}_{\mathrm{x}}$ conditions are an artefact of initial precursor concentration ( $\mathrm{Ng}$ et al., 2007). $\mathrm{Ng}$ et al. (2007) saw roughly 3 and 6 fold increases in SOA yields in the toluene and $m$-xylene systems, respectively, when moving from high to low $\mathrm{NO}_{\mathrm{x}}$ conditions, comparable to observations made here.

As discussed earlier, recent reports attribute the production of a greater aerosol yield in low $\mathrm{NO}_{\mathrm{x}}$ systems to chamber conditions favouring formation of the low volatility peroxides from reactions (R3) and (R4) (Stern et al., 1987; Jenkin et al., 2003; Johnson et al., 2004; Song et al., 2005; Ng et al., 2007). However as will be discussed below, the conditions of low $\mathrm{NO}_{\mathrm{x}}$ experiments 5 and 7 also allowed the early production of a variety of other organic oxidation products which may have further contributed to SOA formation and facilitated enhancement of SOA yield.

Elevated $\mathrm{NO}_{\mathrm{x}}$ concentrations, such as those employed during the high $\mathrm{NO}_{\mathrm{x}}$ experiments of this study, lead to interference problems in the inlet chain length chemistry when measuring peroxy radical species using the PERCA technique (Green et al., 2006; Parker, 2007). Consequently, peroxy radical data are presented only for experiments conducted under low $\mathrm{NO}_{\mathrm{x}}$ conditions. Figure 4 displays the temporal evolution of the sum of both hydro and organic peroxy radicals during experiment 5 , during which a rapid rise in peroxy radical concentration was observed from lights on to a concentration plateau of $\sim 175 \mathrm{pptV}$ by $\sim 400 \mathrm{~min}$.

The temporal behaviour of the peroxy radicals during the low $\mathrm{NO}_{\mathrm{x}}$ experiments can be attributed to the constant HONO input and photolysis rate. Upon being introduced into the chamber, HONO was photolysed to yield $\mathrm{OH}$ and NO. Once formed $\mathrm{OH}$ would have reacted rapidly with $\mathrm{CO}$ and the precursor 1,3,5-TMB leading to the production of $\mathrm{HO}_{2}$ and $\mathrm{RO}_{2}$ radicals, respectively. Within the chamber matrix hydro and organic peroxy radicals would have resided in steady state, being formed and then reacted rapidly. Consequently, the rise in radical concentration observed in Figure 4 during the early stages of the experiment, indicates that up to $\sim 400$ min $\mathrm{HO}_{2}$ and $\mathrm{RO}_{2}$ species were produced at a faster rate than they were consumed. The subsequent onset 
of plateau behaviour in radical concentration highlights the point at which the $\mathrm{HO}_{2}+\mathrm{RO}_{2}$ loss rate became constant.

Using the partitioning theory outlined in Sect. 3.3 (Eq. (2)) along with total peroxy radical and NO measurements, it is possible to demonstrate how peroxide production may proceed within the chamber under low $\mathrm{NO}_{\mathrm{x}}$ conditions. Figure $3 \mathrm{~b}$ shows the variation of $\Phi$ with $\left[\mathrm{RO}_{2}\right]$ and [NO], using measured data and assuming the same $\left[\mathrm{HO}_{2}\right] /\left[\mathrm{RO}_{2}\right]$ ratio as produced in the chamber box model of Rickard et al. (2008), i.e. 0.45 . With the NO concentrations no greater than $1 \mathrm{ppbV \text {, }}$ formation of peroxides within the chamber becomes efficient as soon as the photochemistry is initiated and peroxy radicals are formed (see Figs. 1d and 4). Under low $\mathrm{NO}_{\mathrm{x}}$ conditions Eq. (2) predicts that partitioning of $\mathrm{RO}_{2}$ to peroxides is as efficient as $\sim 5 \%$ after only the first 10 min of experiment, a result that contrasts strongly with findings from the high $\mathrm{NO}_{\mathrm{x}}$ cases. Furthermore, Eq. (E2) predicts that partitioning of $\mathrm{RO}_{2}$ to peroxides reached roughly $18 \%$ by the time of the nucleation event of experiment 5. From the results obtained within this work it would appear that $\Phi$ at the point of nucleation exhibits positive correlation with the ultimate SOA yield achieved, i.e. both low $\mathrm{NO}_{\mathrm{x}}$ experiments exhibited the largest $\Phi$ values as well as presenting the largest SOA yields. These experimental findings further strengthen theories which propose a crucial role for organic hydroperoxides in the SOA formation process, both under chamber conditions and potentially under $\mathrm{NO}_{\mathrm{x}}$ limited ambient conditions.

\subsection{Effect of inorganic seed}

A comparison of the two low $\mathrm{NO}_{\mathrm{x}}$ experiments (5 and 7) in Table 2 shows that particle formation occurred $\sim 30 \mathrm{~min}$ earlier when $\mathrm{SO}_{2}$ gas was included in the matrix. This result could be due to slightly higher $\mathrm{OH}$ levels measured during experiment 7 , but is most likely a consequence of $\mathrm{H}_{2} \mathrm{SO}_{4}$ nucleation, which subsequently supplied a condensation surface for the condensable organic oxidation products (Holmes, 2007). In addition to this, seeding the chamber generated a larger number of particles than in other experiments. The peak particle number density during experiment 7 reached roughly $2200 \mathrm{~cm}^{-3}$, compared to only $410 \mathrm{~cm}^{-3}$ during experiment 5 (in the size range $15-690 \mathrm{~nm}$ ). Due to the larger number of particles produced, the mean geometric aerosol diameter of the seeded SOA was slightly smaller than that produced by homogeneous nucleation, i.e. $\sim 400$ compared to $\sim 460 \mathrm{~nm}$.

Various chamber studies have shown that SOA yields generated from a VOC precursor can become enhanced in the presence of an acidic seed (Jang and Kamens, 2001; Czoschke et al., 2003; Jang et al., 2003; Limbeck et al., 2003; Gao et al., 2004; Surratt et al., 2007; Verheggen et al., 2007). Further inspection of Table 2 shows that despite the production of a greater number of particles, the aerosol yield obtained in the presence of $\mathrm{H}_{2} \mathrm{SO}_{4}$ was no greater than the yield obtained during the companion low $\mathrm{NO}_{\mathrm{x}}$ homogeneous

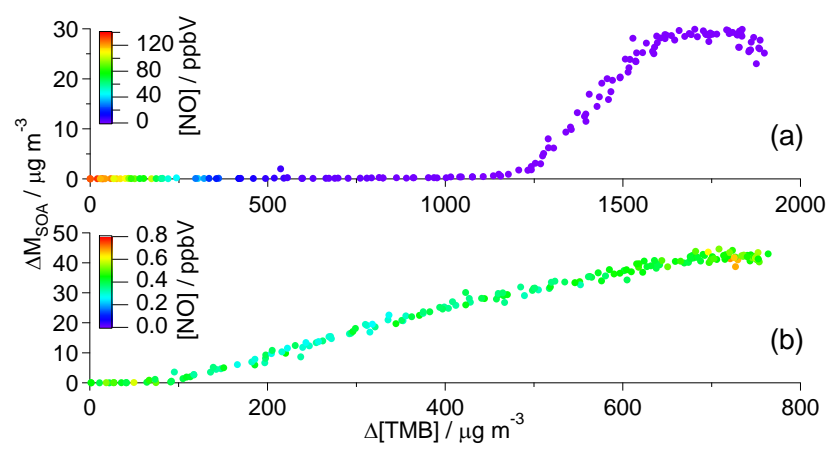

Fig. 5. SOA time-dependent growth curves for (a) experiment 6 (high $\mathrm{NO}_{\mathrm{x}}$ experiment, $\mathrm{VOC} / \mathrm{NO}_{\mathrm{x}} \sim 2: 1$ ) and (b) experiment 7 (low $\mathrm{NO}_{\mathrm{x}}$ experiment, $\mathrm{VOC} / \mathrm{NO}_{\mathrm{x}} \sim 17: 1$ ). $\Delta[\mathrm{TMB}]=$ reacted mass of TMB following initiation of the oxidation chemistry

nucleation experiment. However, the $\mathrm{SO}_{2}$ concentration employed during experiment 7 was somewhat low $(0.4 \mathrm{ppbV}$ compared to $>100 \mathrm{ppbV}$ used by other workers, e.g. Edney et al., 2005; Kleindienst et al., 2006; Metzger et al., 2008b); hence it is possible that the resultant $\left[\mathrm{H}_{2} \mathrm{SO}_{4}\right]$ (i.e. a limit of $1.5 \mu \mathrm{g} \mathrm{m}^{-3}$ assuming full conversion of $\mathrm{SO}_{2}$ to $\mathrm{SO}_{4}^{2-}$ ) was too low to facilitate the acid seed effect. Therefore, with this in mind and with a lack of repeat seed experiments, the result of "no yield enhancement" for TMB-SOA in the presence of $\mathrm{H}_{2} \mathrm{SO}_{4}$ is not conclusive, but is in line with findings presented by $\mathrm{Ng}$ et al. for two other aromatic systems: toluene and $m$-xylene (Ng et al., 2007). A more exhaustive study investigating the effect of acid seeding on TMB-SOA has been produced recently by Metzger et al. (2008b).

\subsection{Time-dependent SOA growth curves}

In order to help elucidate the mechanisms underlying SOA formation in the TMB system, a series of time-dependent SOA growth curves have been generated, following methods employed by Song, $\mathrm{Ng}$ and co-workers (Song et al., 2005; Ng et al., 2007). The time-dependent growth curves essentially comprise a plot of SOA mass formed versus the amount of VOC reacted. Figure 5a presents the growth curve for experiment 6 , a typical example of the high $\mathrm{NO}_{\mathrm{x}}$ system $\left(\mathrm{VOC} / \mathrm{NO}_{\mathrm{x}} \sim 2: 1\right)$. Initial inspection reveals the significant incubation period noted previously as the chamber concentration of $\mathrm{NO} \rightarrow 0$. The incubation period is followed by a linear increase in SOA mass with consumption of the TMB. The growth curve eventually reaches a plateau followed by decay due to particle deposition. Growth curves for all high $\mathrm{NO}_{\mathrm{x}}$ experiments with $\mathrm{VOC} / \mathrm{NO}_{\mathrm{x}} \sim 2: 1$ (not shown) exhibit similar behaviour, with all profiles displaying similar slopes and with all nucleation events occurring within a narrow band of reacted TMB. The time-dependent growth curves for the low $\mathrm{NO}_{\mathrm{x}}$ experiments are also linear following nucleation but, as noted earlier, are preceded by a much 
shorter incubation period than those of the high $\mathrm{NO}_{\mathrm{x}}$ systems. As an example, Fig. 5b displays the growth curve for experiment 7.

As noted in Sects. 3.3 and 3.4 a time delay was observed between $[\mathrm{NO}] \rightarrow 0$ and the nucleation event in high $\mathrm{NO}_{\mathrm{x}}$ experiments 4 and 6 , which was comparable in duration to the incubation period clearly evident in the growth curves of the low $\mathrm{NO}_{\mathrm{x}}$ experiments (e.g. Fig. 5b). As shown above, the formation of hydroperoxides in the low $\mathrm{NO}_{\mathrm{x}}$ system is likely to be extremely efficient even very early into the experiment. Consequently, if organic hydroperoxides are pivotal in TMB-SOA formation, the incubation period observed under low $\mathrm{NO}_{\mathrm{x}}$ conditions (and the further time delay under high $\mathrm{NO}_{\mathrm{x}}$ conditions) could be indicative of the time required for their gas phase concentrations to build to sufficient levels such that their saturation vapour pressure relative to the particle phase is exceeded. It is also possible that the presence of a time delay in certain high $\mathrm{NO}_{\mathrm{x}}$ experiments and the incubation zone in the absence of $\mathrm{NO}_{\mathrm{x}}$ are a consequence of the SOA forming species consisting of later stage oxidation products which form further down the oxidation chain, i.e. from further reaction of primary products (including certain peroxides, see discussion in Sect. 3.9). Growth curves displaying similar behaviour to those derived from the current study were presented by Song et al. (2005) for the $m$-xylene system.

\subsection{The gas phase organic compounds}

\subsubsection{The 1,3,5-trimethylbenzene atmospheric oxidation mechanism}

Before reporting the observations derived from the CIRTOF-MS measurements, we first outline the likely atmospheric oxidation processes of TMB that might lead to SOA formation. Atmospheric oxidation of TMB occurs primarily by reaction with the $\mathrm{OH}$ radical, and may essentially be separated into two distinct pathways. One pathway is reaction via $\mathrm{OH}$ addition to the aromatic ring, which may ultimately lead to ring cleavage (pathway $P i$ ), while the other involves hydrogen abstraction from a methyl group (pathway $P i i)$. In general, the more substituted the aromatic ring, the more important the ring fragmentation route (Johnson et al., 2005; Bloss et al., 2005b). A simplified mechanism for the photochemical degradation of TMB, highlighting the most important atmospheric oxidation routes, is displayed in Fig. 6. This scheme has been constructed through an amalgamation of previous descriptions of the benzene and toluene oxidation systems (Yu et al., 1997; Atkinson, 2000; Bohn, 2001; Calvert et al., 2002; Johnson et al., 2004, 2005), the MCMv3.1 TMB subset (extracted from the MCM website (http://mcm.leeds.ac.uk/MCM), Bloss et al., 2005a, 2005b) and measurements made by CIR-TOF-MS during this study:
(Pi) $\mathrm{OH}$ Addition to the aromatic ring. The principal atmospheric oxidation route for TMB involves the addition of $\mathrm{OH}$ to the aromatic ring (branching ratio of 0.97 in the MCMv3.1), initially forming an $\mathrm{OH}$-aromatic adduct (a trimethyl hydroxycyclohexadienyl radical; compound $\mathrm{B}$ in Fig. 6). In the presence of atmospheric levels of $\mathrm{O}_{2}$ this radical is in equilibrium with its equivalent $\mathrm{OH}$-aromatic$\mathrm{O}_{2}$ adduct (a trimethyl hydroxycyclohexadienyl peroxy radical) (C). The $\mathrm{OH}$-aromatic- $\mathrm{O}_{2}$ adduct (C) can either subsequently decompose to yield $\mathrm{HO}_{2}$ and the ring retaining product 2,4,6-trimethylphenol (D), or most likely will undergo internal rearrangement to generate an $\mathrm{O}_{2}$-bridged trimethyl peroxide bicyclic radical (E) (branching ratio of 0.96 in MCMv3.1). The $\mathrm{O}_{2}$-bridged trimethyl peroxide bicyclic radical (E) can subsequently degrade through various stages of isomerisation, decomposition and scission to form the epoxy-oxy species $(\mathrm{H})$ (path fraction of 0.15 in MCMv3.1). The epoxy-oxy compound can decompose to give a variety of lower molar mass oxygenates (e.g. compounds I and J). However, in the atmosphere the bicyclic peroxide radical (E) will most likely undergo reaction with $\mathrm{O}_{2}$ to form the peroxy radical equivalent (K) (path fraction of 0.85 in MCMv3.1). The yields of initial products formed after addition of $\mathrm{OH}$ to the aromatic ring of TMB in MCMv3.1 are 0.79, 0.14, and 0.04 for the trimethyl peroxide bicyclic peroxy radical $(\mathrm{K})$, the epoxy-oxy species $(\mathrm{H})$ and 2,4,6-trimethylphenol (D), respectively. Depending on the amount of $\mathrm{NO}_{\mathrm{x}}$ present, the peroxide bicyclic peroxy radical $(\mathrm{K})$ will degrade via a number of intermediary steps to produce a range of $\mathrm{O}_{2^{-}}$ bridged oxygenated and nitrated compounds (compounds L$\mathrm{P}$ ). Some of the larger oxygenated and nitrated ring-retaining products, including the multi-functional $\mathrm{O}_{2}$-bridged species shown in Fig. 6, are likely to be sufficiently non-volatile to partition into the organic aerosol phase (Johnson et al., 2004, 2005). Once inside the particle phase, these types of multifunctional compounds can take part in certain association reactions (Johnson et al., 2005).

Further oxidation and ring opening processes (mainly through the oxy radical $(\mathrm{N})$ ) will yield an array of lower molecular mass carbonyl (including methyl glyoxal), unsaturated $\gamma$-dicarbonyl, acid and furanone species, some of which are shown in Fig. 6 (e.g. compounds Q-S). These low molecular mass ring fragmentation products have a tendency to be multi-functional and can be unsaturated, and therefore are generally more reactive than the parent TMB and can be oxidised further through reactions with $\mathrm{OH}$ and $\mathrm{O}_{3}$ and $\mathrm{NO}_{3}$. A selection of likely, further reaction products are shown in Fig. 6. Some of these products, e.g. 3-methyl maleic anhydride (citraconic anhydride) (AB) and 3,5-dimethyl-5(2H)-2furanone (S), can be highly polar and less volatile, and hence may be able to transfer into the organic aerosol phase (Kleindienst et al., 1999; Johnson et al., 2005).

(Pii) Hydrogen abstraction from a pendant methyl group. $\mathrm{OH}$ initiated hydrogen abstraction from a pendant methyl group constitutes the alternative oxidation route for TMB in 


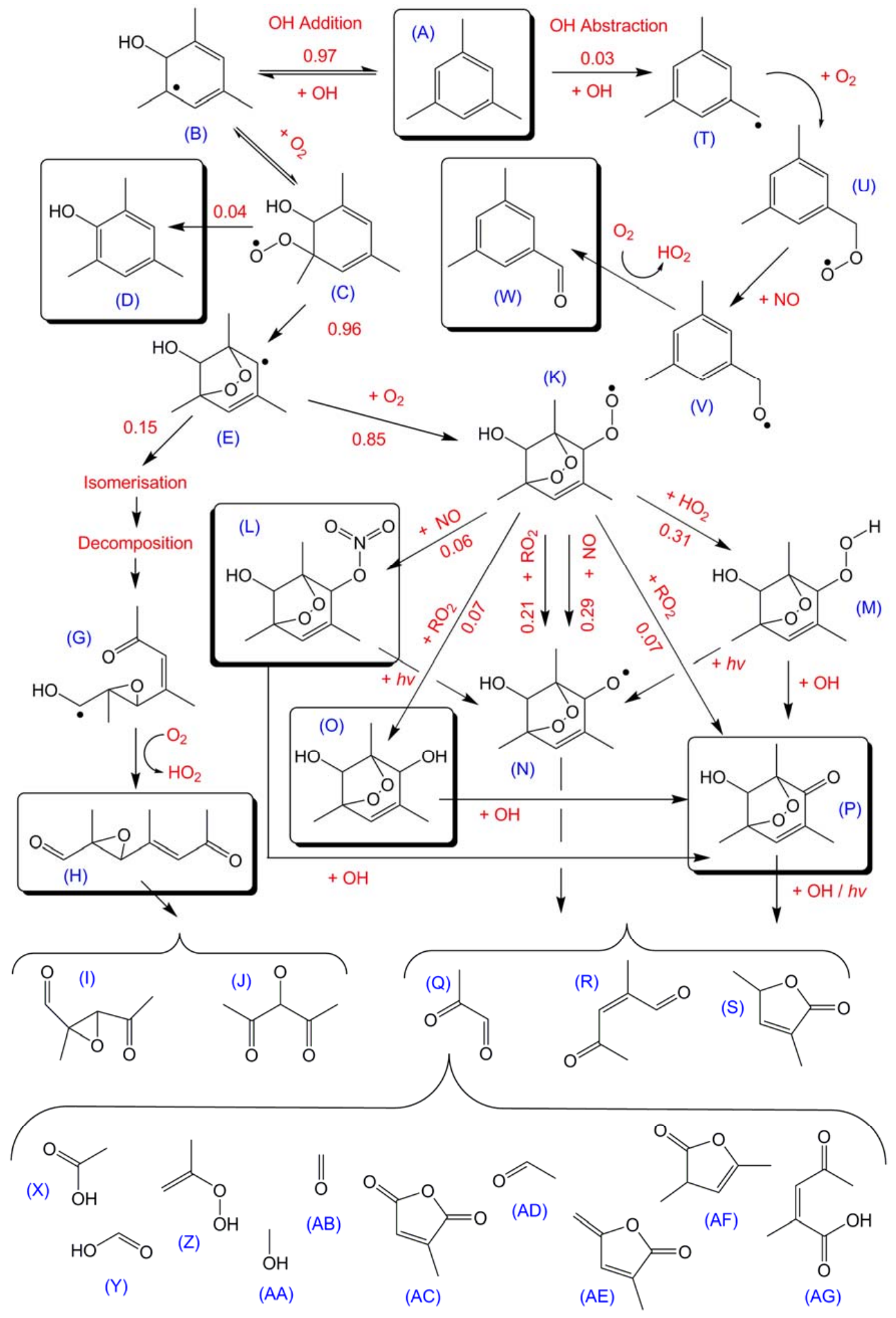

Fig. 6. Mechanism summary of $\mathrm{OH}$ radical-induced photooxidation of 1,3,5-trimethylbenzene. Key primary and secondary product formation shown, branching ratios are taken from MCMv3.1 (http://mcm.leeds.ac.uk/MCM) (see text). 


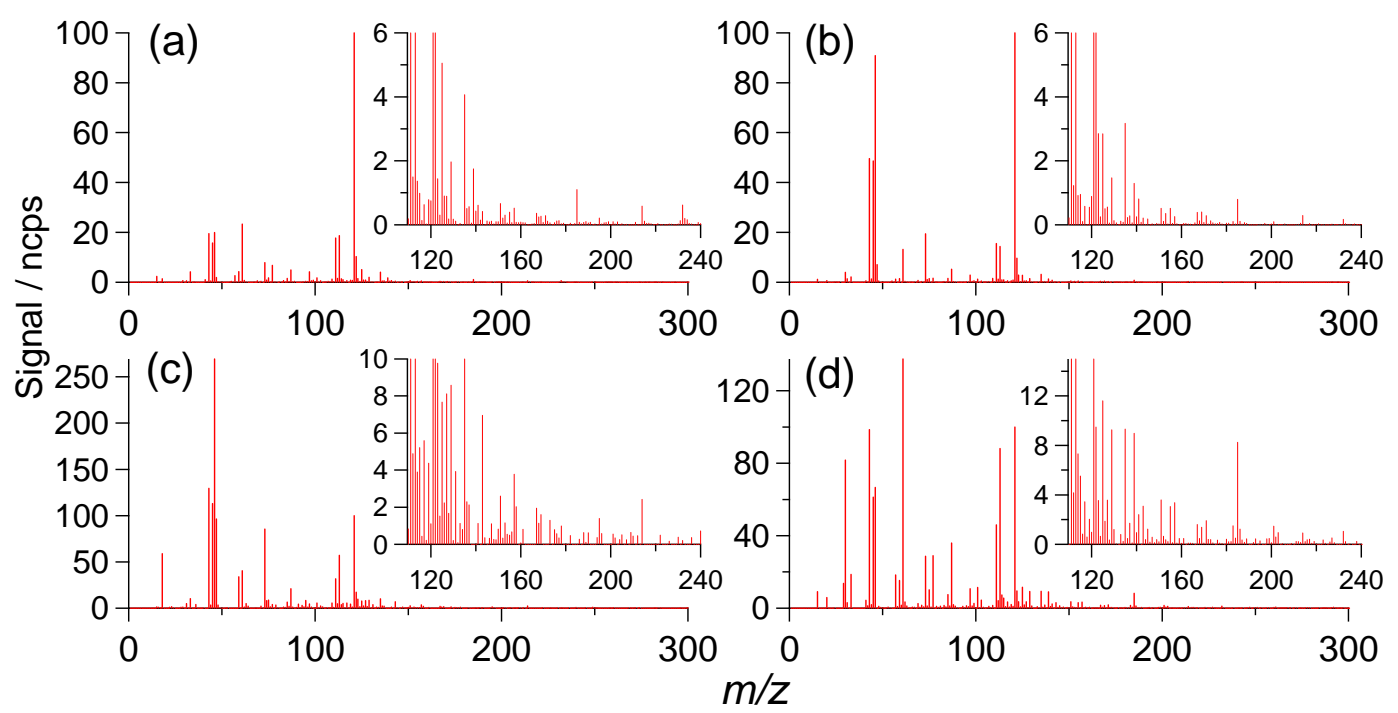

Fig. 7. Comparison of CIR-MS mass spectra recorded $400 \mathrm{~min}$ after lights on for (a) experiment 6 (VOC/NO $\sim 2: 1$ ), (b) experiment 2 (VOC/NO $\mathrm{N}_{\mathrm{x}} \sim 2: 1$, NO only), (c) experiment $3\left(\mathrm{VOC} / \mathrm{NO}_{\mathrm{x}} \sim 1: 2\right)$ and (d) experiment 7 (low $\mathrm{NO}_{\mathrm{x}}$, $\mathrm{VOC} / \mathrm{NO}_{\mathrm{x}} \sim 17: 1$ ). Each mass spectrum corresponds to data accumulation over a ten-minute period.

the atmosphere, and represents the major ring retaining pathway (other than the formation of 2,4,6-trimethyl phenol as described above). Eventually, following hydrogen abstraction, reaction with $\mathrm{O}_{2}$, and subsequent radical reactions (e.g. with $\mathrm{NO}, \mathrm{RO}_{2}$, and $\mathrm{HO}_{2}$ ), 3,5 dimethyl benzaldehyde (W) is formed with a yield of $\sim 0.03$ according to MCMv3.1 (Bloss et al., 2005b).

\subsubsection{Measurement of the gas phase organic compounds}

Figure 7a-d displays the CIR-TOF-MS mass spectra recorded after $400 \mathrm{~min}$ of irradiation during experiments 6 , 3,2 and 7, with $\mathrm{VOC} / \mathrm{NO}_{\mathrm{x}}$ ratios of around $2: 1,1: 2,2: 1$ (NO only) and 17:1, respectively. All of the CIR-TOF-MS data presented within this work have been normalised to $10^{6}$ primary reagent ion counts (i.e. the sum of the $\mathrm{H}_{3} \mathrm{O}^{+}$ and $\mathrm{H}_{3} \mathrm{O}^{+}$. $\left(\mathrm{H}_{2} \mathrm{O}\right)$ signals $)$ and have been background subtracted. Consequently, all signals stated here are quoted in units of normalised counts per second i.e. ncps (de Gouw et al., 2003). In order to show the relative contributions of the various peaks to the total mass spectra, for Fig. 10a-d the $\mathrm{m} / \mathrm{z}, 121$ peaks (i.e. 1,3,5-TMB) have each been assigned a nominal value of $100 \%$ and all other peaks have been scaled accordingly.

During a typical high $\mathrm{NO}_{\mathrm{x}}$ chamber experiment (and depending on the drift cell conditions employed) around 60 peaks were recorded in the mass spectra between $\mathrm{m} / \mathrm{z} 0$ and 300 , with around thirty peaks possessing a mass greater than that of the precursor VOC $(\mathrm{m} / \mathrm{z}, 121)$. In contrast, roughly fifty significant features were recorded during the low $\mathrm{NO}_{\mathrm{x}}$ experiments, with around twenty of those possessing a mass greater than that of the precursor. It should be noted, however, that this difference could be attributed to the use of a lower precursor concentration during the low $\mathrm{NO}_{\mathrm{x}}$ studies where detection limits of the instrument become an issue (see Wyche et al., 2007 for further information regarding detection limits). The number of spectral features quoted here includes features present due to fragment ions as well as parent ions, and hence the number of peaks recorded does not necessarily represent the total diversity of organic species in the chamber. For brief periods during certain experiments, the electric field applied across the collision cell in the CIRTOF-MS drift tube was increased to produce more energetic collisions, and thus to identify and help exclude any possible molecular ion water cluster products (i.e. $\left.\mathrm{MH}^{+} .\left(\mathrm{H}_{2} \mathrm{O}\right)_{n}\right)$.

The major spectral features common to all experiments are listed in Table 4 along with, where possible, a tentative compound assignment. Table 4 also gives a chamber "appearance time" for each compound, defined as the time at which the signal for a given spectral feature exceeds the mean background signal plus three times its standard deviation. All compound assignments have been made using a combination of information, namely TOF-MS accurate mass measurements, appearance time, subsequent temporal profile, and data available from the MCMv3.1 box model simulations (see Rickard et al., 2008).

\subsubsection{Behaviour of the gas phase organics under high $\mathrm{NO}_{\mathrm{x}}$ conditions}

As a focus for discussion, the evolution of the entire measured VOC system of experiment 6 is presented in Fig. 8. General features of note include the appearance of most species within the first $50-100 \mathrm{~min}$ of the experiment, 
Table 4. Most major VOC contributors to the gas phase as measured by CIR-TOF-MS. Measured $m / z$, actual "unprotonated" compound mass, approximate peak signal intensity, appearance time and tentative assignments are included. MCM species names are included and can be used for navigation around the MCMv3.1 TMB degradation scheme via the MCM website (http://mcm.leeds.ac.uk/MCM).

\begin{tabular}{|c|c|c|c|c|c|c|c|c|c|}
\hline \multirow{3}{*}{$\begin{array}{c}\text { Mass } \\
\text { Measured } \\
m / z \\
\text { (Actual/ Da) }\end{array}$} & \multirow{3}{*}{$\begin{array}{l}\text { Peak } \\
\text { Signal/ } \\
\text { ncps }\end{array}$} & \multirow{3}{*}{$\begin{array}{c}\text { Tentative Assignment } \\
\text { Name (MCM designation)/ } \\
\text { (Fig. } 6 \text { identifier) }\end{array}$} & \multicolumn{7}{|c|}{ Appearance Time / minutes } \\
\hline & & & \multicolumn{7}{|c|}{ Experiment } \\
\hline & & & 1 & 2 & 3 & 4 & 5 & 6 & 7 \\
\hline $\begin{array}{c}232.20 \\
(231.20)\end{array}$ & 200 & $\begin{array}{c}\text { 1,3,5-trimethyl-4-nitrooxy- } \\
\text { 6,7-dioxa-bicyclo[3.2.1] oct- } \\
\text { 2-en-8-ol } \\
\text { (TM135BPNO3)/(L) }\end{array}$ & 120 & 90 & $\mathrm{n} / \mathrm{m}$ & 51 & 36 & 51 & 3 \\
\hline $\begin{array}{l}214.15 \\
(214.20)\end{array}$ & 200 & $\begin{array}{l}\text { TM135BPNO3 Fragment: } \\
\mathrm{MH}^{+}\left[-\mathrm{H}_{2} \mathrm{O}\right]\end{array}$ & 96 & 100 & 87 & 81 & 33 & 12 & 3 \\
\hline $\begin{array}{c}185.20 \\
(184.19)\end{array}$ & 300 & $\begin{array}{c}\text { 8-hydroxy-1,3,5-trimethyl- } \\
\text { 6,7-dioxa-bicyclo[3.2.1]oct- } \\
\text { 3-en-2-one } \\
\text { (TM135OBPOH)/(P) }\end{array}$ & 105 & 130 & $288^{*}$ & 108 & 24 & 60 & 15 \\
\hline & & $\begin{array}{l}\text { 2-methyl-3-(1-methyl-3-oxo- } \\
\text { but-1-enyl)-oxirane-2- } \\
\text { carboxylic acid } \\
\text { (TM135MUO2H) }\end{array}$ & & & & & & & \\
\hline $\begin{array}{c}169.22 \\
(169.20)\end{array}$ & 70 & $\begin{array}{l}\text { 1,3,5-trimethyl-6,7-dioxa- } \\
\text { bicyclo[3.2.1] oct-3-ene-2,8- } \\
\text { diol (TM135BP2OH)/(O) } \\
\text { Fragment: } \mathrm{MH}^{+}\left[-\mathrm{H}_{2} \mathrm{O}\right]\end{array}$ & 36 & 93 & $\mathrm{n} / \mathrm{m}$ & 69 & 36 & 42 & 3 \\
\hline$(168.19)$ & & $\begin{array}{c}\text { 2-methyl-3-(1-methyl-3-oxo- } \\
\text { but-1-enyl)-oxirane-2- } \\
\text { carbaldehyde } \\
\text { (TM135OXMUC) }\end{array}$ & & & & & & & \\
\hline $\begin{array}{c}167.18 \\
(166.17)\end{array}$ & 120 & $\begin{array}{l}\text { 3,5-dimethyl- } \\
\text { benzenecarboperoxoic acid } \\
(\mathrm{TMBCO} 3 \mathrm{H})\end{array}$ & 147 & 177 & $\mathrm{n} / \mathrm{m}$ & 81 & 114 & 63 & $\mathrm{n} / \mathrm{m}$ \\
\hline $\begin{array}{c}157.20 \\
(156.18)\end{array}$ & 150 & $\begin{array}{c}\text { 5-hydroxy-4-methyl-hept-3- } \\
\text { ene-2,6-dione } \\
\text { (C7M2CO5OH) }\end{array}$ & 150 & 126 & 240 & 99 & 102 & 66 & 24 \\
\hline $\begin{array}{c}155.18 \\
(154.16)\end{array}$ & 120 & $\begin{array}{l}\text { 4-methyl-hept-4-ene-2,3,6- } \\
\text { trione }(\mathrm{C} 7 \mathrm{M} 3 \mathrm{CO})\end{array}$ & $453^{*}$ & 171 & $\mathrm{n} / \mathrm{m}$ & 111 & 183 & 129 & $30^{*}$ \\
\hline $\begin{array}{c}153.22 \\
(152.19)\end{array}$ & 100 & $\begin{array}{l}\text { (3,5-dimethyl-phenyl)- } \\
\text { methyl-hydroperoxide } \\
\text { (TMBOOH) }\end{array}$ & 72 & 120 & $\mathrm{n} / \mathrm{m}$ & 102 & 120 & 120 & $120^{*}$ \\
\hline $\begin{array}{c}151.17 \\
(150.17)\end{array}$ & 160 & $\begin{array}{l}\text { 3,5-dimethylbenzoic acid } \\
\text { (TMBCO2H) }\end{array}$ & 105 & 84 & $465^{*}$ & 72 & 135 & 60 & $39 *$ \\
\hline
\end{tabular}


Table 4. Continued.

\begin{tabular}{|c|c|c|c|c|c|c|c|c|c|}
\hline \multirow{3}{*}{$\begin{array}{c}\text { Mass } \\
\text { Measured } \\
m / z \\
\text { (Actual/ Da) }\end{array}$} & \multirow{3}{*}{$\begin{array}{l}\text { Peak } \\
\text { Signal/ } \\
\text { ncps }\end{array}$} & \multirow{3}{*}{$\begin{array}{c}\text { Tentative Assignment } \\
\text { Name (MCM designation)/ } \\
\text { (Fig. } 6 \text { identifier) }\end{array}$} & \multicolumn{7}{|c|}{ Appearance Time / minutes } \\
\hline & & & \multicolumn{7}{|c|}{ Experiment } \\
\hline & & & 1 & 2 & 3 & 4 & 5 & 6 & 7 \\
\hline \multirow[t]{3}{*}{$\begin{array}{c}145.17 \\
(144.13)\end{array}$} & 50 & $\begin{array}{l}\text { 2-methyl-4-oxo-pent-2- } \\
\text { eneperoxoic acid } \\
(\mathrm{C} 5 \mathrm{CODBCO} 3 \mathrm{H})\end{array}$ & 309 & $180^{*}$ & $\mathrm{n} / \mathrm{m}$ & 141 & 81 & $249^{*}$ & $\mathrm{n} / \mathrm{m}$ \\
\hline & & $\begin{array}{l}\text { 2-hydroxy-2-methyl-3,4- } \\
\text { dioxo-pentanal } \\
(\mathrm{C} 6 \mathrm{CO} 3 \mathrm{MOH})\end{array}$ & & & & & & & \\
\hline & & $\begin{array}{l}\text { 2-oxo-propionic acid 1- } \\
\text { methyl-2-oxo-ethyl ester } \\
\quad(\mathrm{C} 23 \mathrm{O} 3 \mathrm{MCHO})\end{array}$ & & & & & & & \\
\hline 143.19 & 120 & Unidentified & $366^{*}$ & $*$ & $406^{*}$ & 129 & 78 & 75 & $30 *$ \\
\hline 141.18 & 140 & Unidentified & 126 & 111 & $* *$ & 132 & 138 & 75 & 60 \\
\hline $\begin{array}{c}139.18 \\
(138.16)\end{array}$ & 400 & $\begin{array}{l}\text { 3,5-dimethyl-phenyl- } \\
\text { hydroperoxide (DMPHOOH) }\end{array}$ & $309^{*}$ & 78 & $* *$ & 51 & 3 & 66 & 3 \\
\hline \multirow[t]{2}{*}{$\begin{array}{c}137.19 \\
(136.19)\end{array}$} & 220 & $\begin{array}{l}\text { 2,4,6-trimethyl phenol } \\
\text { (TM135BZOL)/(D) }\end{array}$ & 81 & 75 & 96 & 54 & $* *$ & 15 & 15 \\
\hline & & $\begin{array}{l}\text { (3,5-dimethyl-phenyl)- } \\
\text { methanol (TMBOH) }\end{array}$ & & & & & & & \\
\hline (136.15) & & m-xyloquinone & & & & & & & \\
\hline 136.09 & 400 & Unidentified organic nitrate & 114 & 132 & 141 & 87 & 45 & 96 & $\mathrm{n} / \mathrm{m}$ \\
\hline $\begin{array}{c}135.18 \\
(134.18)\end{array}$ & 1000 & $\begin{array}{l}\text { 3,5-dimethyl benzaldehyde } \\
\text { (TMBCHO } /(\mathrm{W})\end{array}$ & 63 & 78 & 93 & 57 & 30 & 39 & 18 \\
\hline (134.09) & & $\begin{array}{l}\text { 2-hydroxy-2-methyl-3-oxo- } \\
\text { propaneperoxoic acid } \\
(\mathrm{CHOMOHCO} \mathrm{H})\end{array}$ & & & & & & & \\
\hline (134.09) & & $\begin{array}{l}\text { 2-hydroxy-3-oxo- } \\
\text { butaneperoxoic acid } \\
\text { (CO2H3CO3H) }\end{array}$ & & & & & & & \\
\hline (134.09) & & malic acid & & & & & & & \\
\hline \multirow[t]{2}{*}{$\begin{array}{c}129.17 \\
(128.13)\end{array}$} & 500 & $\begin{array}{l}\text { 2-methyl-4-oxo-pent-2-enoic } \\
\text { acid (C5CODBCO2H) }\end{array}$ & 84 & 93 & 168 & 66 & 3 & 72 & 33 \\
\hline & & $\begin{array}{l}\text { 3-acetyl-2-methyl-oxirane-2- } \\
\text { carbaldehyde (EPXMALKT) }\end{array}$ & & & & & & & \\
\hline 127.17 & 300 & Related to Bicyclic Signals & 90 & 90 & 144 & 96 & 99 & 57 & 27 \\
\hline
\end{tabular}


Table 4. Continued.

\begin{tabular}{|c|c|c|c|c|c|c|c|c|c|}
\hline \multirow{3}{*}{$\begin{array}{c}\text { Mass } \\
\text { Measured } \\
m / z \\
\text { (Actual/ Da) }\end{array}$} & \multirow{3}{*}{$\begin{array}{l}\text { Peak } \\
\text { Signal/ } \\
\text { ncps }\end{array}$} & \multirow{3}{*}{$\begin{array}{c}\text { Tentative Assignment } \\
\text { Name (MCM designation)/ } \\
\text { (Fig. } 6 \text { identifier) }\end{array}$} & \multicolumn{7}{|c|}{ Appearance Time / minutes } \\
\hline & & & \multicolumn{7}{|c|}{ Experiment } \\
\hline & & & 1 & 2 & 3 & 4 & 5 & 6 & 7 \\
\hline $\begin{array}{c}125.15 \\
(125.10)\end{array}$ & 1200 & $\begin{array}{l}\text { Bicyclic Fragment: } \\
\qquad\left[\mathrm{C}_{6} \mathrm{H}_{5} \mathrm{O}_{3}\right] \mathrm{H}^{+}\end{array}$ & 99 & 102 & 69 & 45 & 3 & 33 & 3 \\
\hline 123.17 & 400 & Unidentified & $* *$ & $* *$ & $183^{*}$ & $* *$ & $* *$ & $* *$ & $* *$ \\
\hline \multirow[t]{2}{*}{$\begin{array}{c}119.18 \\
(118.09)\end{array}$} & 200 & $\begin{array}{c}\text { 2-hydroperoxy-2-methyl- } \\
\text { malonaldehyde } \\
(\mathrm{C} 3 \mathrm{MDIALOOH})\end{array}$ & 90 & 75 & $* *$ & 123 & 33 & 69 & $3^{*}$ \\
\hline & & Succinic acid & & & & & & & \\
\hline $\begin{array}{c}117.14 \\
(116.12)\end{array}$ & 140 & $\begin{array}{l}\text { 3-hydroxy-pentane-2,4-dione } \\
\text { (C5CO243OH) }\end{array}$ & 174 & 129 & 183 & 84 & 42 & 81 & 12 \\
\hline $\begin{array}{c}115.13 \\
(114.10)\end{array}$ & 250 & $\begin{array}{l}\text { pentane-2,3,4-trione } \\
\quad(\mathrm{C} 5 \mathrm{CO} 234)\end{array}$ & 153 & 108 & 183 & 111 & 18 & 3 & $33^{*}$ \\
\hline $\begin{array}{c}113.13 \\
(112.08)\end{array}$ & 7400 & $\begin{array}{l}\text { methyl maleic anhydride } \\
(\mathrm{MMALANHY}) /(\mathrm{AF})\end{array}$ & 15 & 15 & 33 & 15 & 9 & 3 & 6 \\
\hline (112.13) & & $\begin{array}{l}\text { 2-methyl-4-oxo-2-pentenal } \\
\text { (C5MDICARB)/(R) }\end{array}$ & & & & & & & \\
\hline (112.13) & & $\begin{array}{l}\text { 3,5-dimethyl-3(2H)-2- } \\
\text { furanone/(AF) }\end{array}$ & & & & & & & \\
\hline (112.13) & & $\begin{array}{l}\text { 3,5-dimethyl-5(2H)-2- } \\
\text { furanone (MXFUONE)/(S) }\end{array}$ & & & & & & & \\
\hline $\begin{array}{c}111.12 \\
(110.04)\end{array}$ & 6000 & $\begin{array}{l}3 \text { methyl-5-methylidene-5- } \\
(2 \mathrm{H}) \text { furanone }\end{array}$ & 72 & 60 & 105 & 66 & 15 & 21 & 39 \\
\hline $\begin{array}{l}109.15 \\
(109.10)\end{array}$ & 400 & $\begin{array}{l}\text { TM135BPNO3 Fragment: } \\
\mathrm{MH}^{+}\left[-\mathrm{NO}_{3} .3\left(\mathrm{CH}_{3}\right) \mathrm{O}\right]\end{array}$ & 84 & 75 & 51 & 60 & 3 & 54 & 3 \\
\hline $\begin{array}{c}103.11 \\
(102.09)\end{array}$ & 150 & $\begin{array}{l}\text { 2-hydroxy-2-methyl- } \\
\text { malonaldehyde } \\
\text { (C3MDIALOH) }\end{array}$ & 150 & 126 & $* *$ & 126 & 93 & 12 & 27 \\
\hline $\begin{array}{c}101.13 \\
(100.07)\end{array}$ & 400 & 2,3-dioxobutanal & 126 & 90 & 129 & 84 & 60 & 12 & 15 \\
\hline 99.12 & 160 & Unidentified & 183 & 171 & $\mathrm{n} / \mathrm{m}$ & $177^{*}$ & 366 & 99 & $30^{*}$ \\
\hline 97.13 & 1000 & Unidentified & 72 & 78 & 102 & 81 & 51 & 9 & 33 \\
\hline 87.10 & 1200 & Related to Bicyclic Signals & 117 & 75 & 123 & 90 & 42 & 12 & 24 \\
\hline $\begin{array}{c}85.11 \\
(85.13) \\
(84.07)\end{array}$ & 500 & $\begin{array}{c}m / z 113 \text { Fragment: } \\
\mathrm{MH}^{+}[-\mathrm{CO}] \\
\text { butenedial }\end{array}$ & 84 & 63 & 81 & 51 & 63 & 33 & 27 \\
\hline
\end{tabular}


Table 4. Continued.

\begin{tabular}{|c|c|c|c|c|c|c|c|c|c|}
\hline \multirow{3}{*}{$\begin{array}{c}\text { Mass } \\
\text { Measured } \\
m / z \\
\text { (Actual/ Da) }\end{array}$} & \multirow{3}{*}{$\begin{array}{l}\text { Peak } \\
\text { Signal/ } \\
\text { ncps }\end{array}$} & \multirow{3}{*}{$\begin{array}{c}\text { Tentative Assignment } \\
\text { Name (MCM designation)/ } \\
\text { (Fig. } 6 \text { identifier) }\end{array}$} & \multicolumn{7}{|c|}{ Appearance Time / minutes } \\
\hline & & & \multicolumn{7}{|c|}{ Experiment } \\
\hline & & & 1 & 2 & 3 & 4 & 5 & 6 & 7 \\
\hline $\begin{array}{c}77.07 \\
(76.05)\end{array}$ & 1400 & hydroxy acetic acid & 99 & 135 & 168 & 90 & 36 & 63 & 15 \\
\hline $\begin{array}{c}75.09 \\
(74.08)\end{array}$ & 400 & hydroxyacetone & 141 & 66 & 147 & 105 & 72 & 66 & 3 \\
\hline (74.04) & & oxo-acetic acid ( $\mathrm{HCOCO} 2 \mathrm{H})$ & & & & & & & \\
\hline $\begin{array}{c}73.07 \\
(72.06)\end{array}$ & 1600 & methyl glyoxal (MGLYOX)/(Q) & 36 & 30 & 39 & 15 & 9 & 36 & 15 \\
\hline $\begin{array}{c}61.07 \\
(60.05)\end{array}$ & 6000 & acetic acid $(\mathrm{CH} 3 \mathrm{CO} 2 \mathrm{H}) /(\mathrm{X})$ & 36 & 72 & 60 & 90 & 12 & 18 & 3 \\
\hline$(60.50)$ & & glycoaldehyde & & & & & & & \\
\hline (88.06) & & pyruvic acid fragment & & & & & & & \\
\hline (90.08) & & lactic acid fragment & & & & & & & \\
\hline $\begin{array}{c}59.08 \\
(58.08)\end{array}$ & 1200 & acetone & $\mathrm{n} / \mathrm{m}$ & $\mathrm{n} / \mathrm{m}$ & 174 & 51 & $72^{*}$ & 207 & 27 \\
\hline $\begin{array}{c}57.10 \\
(57.07 / \\
57.11)\end{array}$ & 1000 & $\begin{array}{l}\text { carbonyl/hydrocarbon } \\
\text { Fragment: }\left[\mathrm{C}_{3} \mathrm{H}_{5} \mathrm{O}^{+}\right] /\left[\mathrm{C}_{4} \mathrm{H}_{9}^{+}\right]\end{array}$ & 225 & 141 & $\mathrm{n} / \mathrm{m}$ & 147 & 114 & 183 & 51 \\
\hline $\begin{array}{c}47.01 \\
(46.03)\end{array}$ & 600 & formic acid/(Y) & 198 & 105 & 69 & 72 & 72 & 252 & $* *$ \\
\hline $46.01(46.01)$ & 5000 & PAN Fragment/organic nitrate: $\left[\mathrm{NO}_{2}^{+}\right]$ & 102 & 105 & 105 & 72 & 93 & 72 & 51 \\
\hline $\begin{array}{c}45.06 \\
(44.05)\end{array}$ & 3500 & $\begin{array}{c}\text { methyl glyoxal Fragment } \\
\text { acetaldehyde } \\
(\mathrm{CH} 3 \mathrm{OOH}) /(\mathrm{AE})\end{array}$ & 63 & 42 & 93 & 48 & 99 & 45 & 12 \\
\hline $\begin{array}{l}43.04 \\
(43.04 / \\
43.09)\end{array}$ & 5000 & $\begin{array}{c}\text { carbonyl/hydrocarbon } \\
\text { Fragment: }\left[\mathrm{C}_{2} \mathrm{H}_{3} \mathrm{O}^{+}\right] /\left[\mathrm{C}_{3} \mathrm{H}_{7}^{+}\right]\end{array}$ & 63 & 18 & 69 & 57 & 3 & 3 & 0 \\
\hline $\begin{array}{c}33.05 \\
(32.04)\end{array}$ & 5000 & methanol $(\mathrm{CH} 3 \mathrm{OH}) /(\mathrm{AA})$ & 105 & 141 & $399^{*}$ & 106 & 132 & 153 & 90 \\
\hline $\begin{array}{c}31.03 \\
(30.03)\end{array}$ & 1000 & formaldehyde $(\mathrm{HCHO}) /(\mathrm{AC})$ & 264 & 159 & $345^{*}$ & $132^{*}$ & $243^{*}$ & 249 & 27 \\
\hline
\end{tabular}

$\mathrm{n} / \mathrm{m}=$ Compound not measured during specific experiment

* = Weak signal, high potential for error in appearance time

** $=$ Signal below detection limit on 10 min time scale, appearance time not reported. 


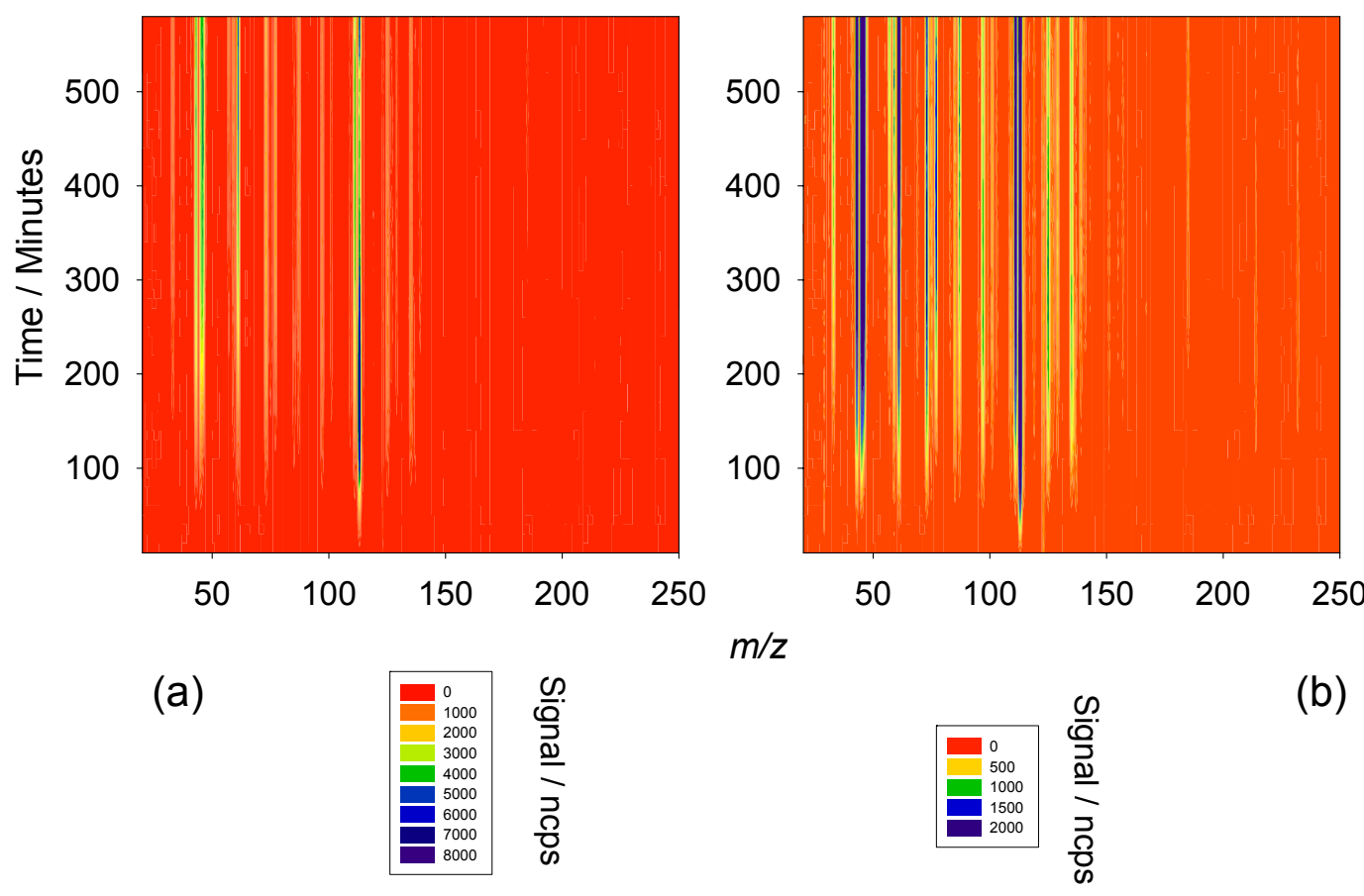

Fig. 8. (a) Evolution of the gas phase organic species during experiment 6 (VOC/NO $\sim 2: 1$ ). (b) Signal intensity (z-axis) scaled to 2000 ncps to reveal lower concentration features.

including many high mass oxidation products. The high $\mathrm{NO}_{\mathrm{x}}$ photooxidation system of TMB is also characterised by a peak in concentration of the heavier species around the midpoint of the experiment ( $\sim 200-300 \mathrm{~min})$. The lower molecular mass features demonstrate a continual rise in intensity up to the end of the experiment.

Looking more closely at the features recorded by CIRTOF-MS (Table 4), it is possible to follow the system evolution as outlined in Fig. 6. Two of the earliest compounds to appear in the oxidation chain are the ringretaining compounds, 2,4,6-trimethylphenol (D) and 3,5dimethylbenzaldehyde (W). Both 2,4,6-trimethylphenol and 3,5-dimethylbenzaldehyde were measured in the chamber as protonated parent ions (i.e. $\mathrm{m} / \mathrm{z} 137$ and 135, respectively); their temporal profiles as measured under the high $\mathrm{NO}_{\mathrm{x}}$ conditions of experiment 6 , are shown in Fig. 9. During experiment 6, 2,4,6-trimethylphenol and 3,5dimethylbenzaldehyde were measured to reach peak concentrations of approximately 2.5 and $7 \mathrm{ppbV}$, respectively.

As described in Sect. 3.7.1, the majority of mass transit in the TMB oxidation system occurs via addition of $\mathrm{OH}$ to the aromatic ring followed by production of the trimethyl peroxide bicyclic radical (E) and its peroxy radical counterpart (K). The various subsequent pathways shown in Fig. 6 can lead to an array of $\mathrm{O}_{2}$-bridged aromatic compounds (L-P). We report here the first firm evidence for the existence of these $\mathrm{O}_{2}$-bridged species along with documentation of their real-time evolution, as measured by the CIR-TOF-MS. As

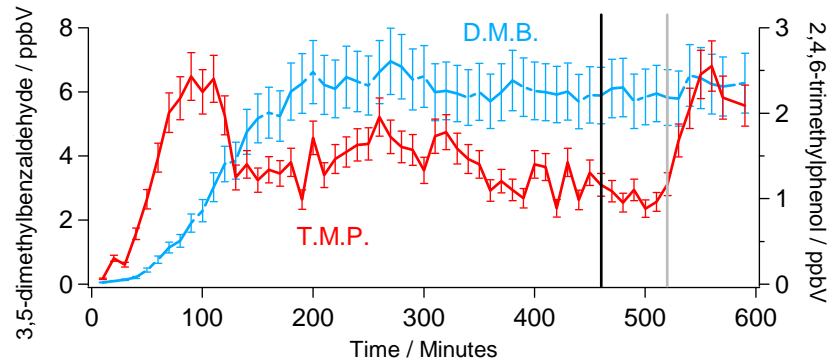

Fig. 9. Temporal evolution of 2,4,6-trimethylphenol and 3,5dimethylbenzaldehyde during high $\mathrm{NO}_{\mathrm{x}}$ experiment 6 . The black vertical line indicates the start of the "dark phase" and the grey vertical line indicates the NO injection time.

summarised in Table 4, peaks consistent with the $\mathrm{O}_{2}$-bridged nitrate (L), diol (O) and ketone (P) were recorded at $\mathrm{m} / \mathrm{z} 232$, 169 and 185 , respectively. Two fragment ions of the nitrate were also measured (at $\mathrm{m} / \mathrm{z} 214$ and 109), as was a signal tentatively assigned to be the aromatic ring fragment of the $\mathrm{O}_{2}$-bridged species $(\mathrm{m} / \mathrm{z}, 125)$. No ion corresponding to the protonated $\mathrm{O}_{2}$-bridged peroxide (M) was measured. Comparison of the measured temporal profiles of the $\mathrm{O}_{2}$-bridged species with simulations using a chamber box model incorporating detailed TMB degradation chemistry taken from the MCMv3.1, is discussed in the companion modelling paper (Rickard et al., 2008). 

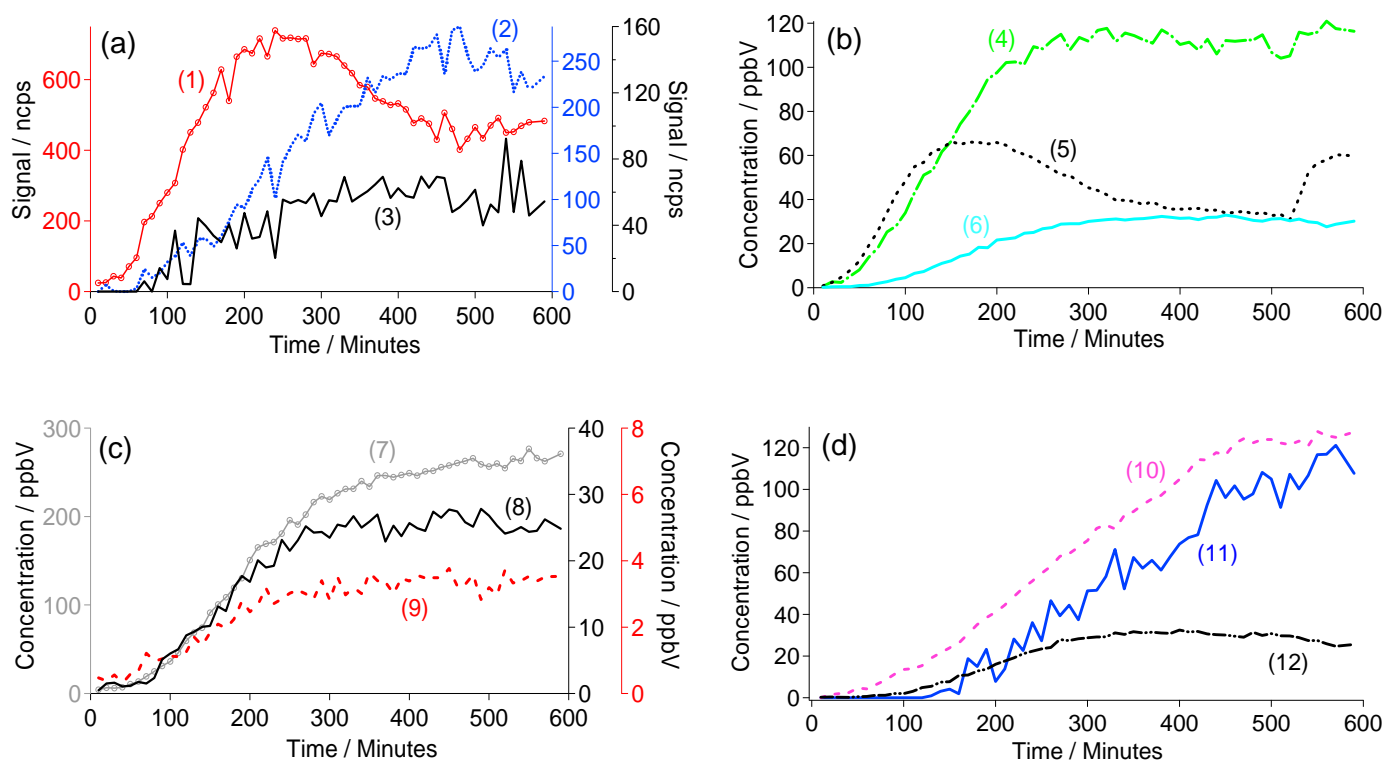

Fig. 10. Temporal evolution of a selection of important VOCs measured during the photooxidation of 1,3,5-TMB in experiment 6 (VOC/NO $\mathrm{NO}_{\mathrm{x}} \sim 2: 1$ ). (a) (1) $\mathrm{O}_{2}$-bridged nitrate, (2) $\mathrm{O}_{2}$-bridged ketone (on right axis), (3) $\mathrm{O}_{2}$-bridged diol fragment, (b) (4) methyl glyoxal, (5) $\mathrm{m} / \mathrm{z}$, 113- isobaric ring opening products, citraconic anhydride, 3,5-dimethyl-3(2H)-2-furanone, 3,5-dimethyl-5(2H)-2-furanone and 2-methyl-4-oxo-2-pentenal, (6) 3 methyl-5-methylidene-5-(2H)-furanone, (c) (7) m/z 43 (carbonyl marker), (8) 2-methyl-4-oxo-pent-2-enoic acid and 3-acetyl-2-methyl-oxirane-2-carbaldehyde, (9) hydroxyl acetone and (d) (10) acetic acid, (11) formic acid, (12) hydroxy acetic acid. Chamber lights were switched off for the "dark phase" at $460 \mathrm{~min}$ followed by NO injection (see text for details).

The measured concentration time profiles of the $\mathrm{O}_{2}$ bridged bicyclic compounds are shown in Fig. 10a. Due to relatively high levels of $\mathrm{NO}$ early in the experiment, the $\mathrm{O}_{2}$ bridged nitrate $(\mathrm{L})$ was the first of the triumvirate to appear in the chamber, at $\sim 10-50$ min during experiment 6 . The $\mathrm{O}_{2}$-bridged nitrate is formed in relatively high yield when compared to the other aromatic systems (Bloss et al., 2005b). As the chamber matrix evolved and levels of $\mathrm{HO}_{2}$ and $\mathrm{RO}_{2}$ began to increase, the $\mathrm{O}_{2}$-bridged diol and ketone (and presumably the peroxide (M): see Rickard et al., 2009) were produced, appearing roughly together at $\sim 40-60 \mathrm{~min}$.

The primary bicyclic nitrate remained in a state of production whilst NO was present in the chamber, up to a peak near $250 \mathrm{~min}$, followed by decay as its rate of loss via oxidation (and/or loss to the aerosol, see Sect. 6.4.1) overtook its rate of production as the precursor TMB was consumed and as chamber $\left[\mathrm{NO}_{\mathrm{x}}\right]$ fell towards zero. The $\mathrm{O}_{2}$-bridged diol and ketone followed a similar profile to the nitrate early in the experiment but continued on a steady rise as $\mathrm{HO}_{2}$ and $\mathrm{RO}_{2}$ became more prevalent within the chamber.

According to the mechanism outlined in Fig. 6, the $\mathrm{O}_{2}$ bridged ketone $(\mathrm{P})$ and alkoxy radical $(\mathrm{N})$ act as conduits for further mass transit through the oxidation system. Both compounds are liable to undergo ring cleavage to yield an array of lower molecular mass oxygenated and nitrated compounds, the first and most abundant of which are methyl glyoxal (Q) and 3,5-dimethyl-5(2H)-2-furanone (S), measured as protonated parent ions at $m / z, 73$ and 113 , respectively.
A variety of oxygenated species, all of nominal mass 112 , appear in the TMB oxidation chain and were measured collectively at $\mathrm{m} / z 113$ (i.e. protonated) by CIR-TOF-MS. Along with 3,5-dimethyl-5(2H)-2-furanone, laboratory studies have identified these to be the furanones, 3,5-dimethyl-3(2H)-2furanone (AF) and 3-methyl-furan-2,5-dione (methyl maleic anhydride) (AC), and the $\delta$-dicarbonyl 2-methyl-4-oxo-2pentenal (R) (Smith et al., 1999). Also observed here in the chamber matrix was a fourth furanone, 3-methy-5methylidene-5(2H)-2-furanone, measured at $\mathrm{m} / z, 111$ (AE) (Smith et al., 1999).

Both methyl glyoxal and the $\mathrm{m} / z 113$ compounds were amongst the first oxidation products to appear in the chamber (after $\sim 3-30 \mathrm{~min}$ ), being formed via a series of highly reactive radical intermediates during the early, $\mathrm{NO}_{\mathrm{x}}$ dominated stages of the high $\mathrm{NO}_{\mathrm{x}}$ experiment. As shown in Fig. 10b, the concentrations of methyl glyoxal, 3-methy-5-methylidene$5(2 \mathrm{H})$-2-furanone and the $\mathrm{m} / z, 113$ species increased rapidly to peaks of $\sim 110,30$ and $65 \mathrm{ppbV}$, at roughly 320,450 and $170 \mathrm{~min}$, respectively. Eventually the chemistry generating these oxidation products reached steady state, as indicated by the observed concentration plateaus.

Throughout the experiment methyl glyoxal, methyl-5methylidiene-5(2H)-2- furanone and the $\mathrm{m} / \mathrm{z} 113$ species were amongst the most dominant features of the mass spectrum, being produced first via the alkoxy radical and the bicyclic nitrate, and subsequently through the $\mathrm{HO}_{2}$ and $\mathrm{RO}_{2}$ controlled pathways. At peak concentrations the (mass 
percent) VOC yields ( $\mathrm{Y}_{\mathrm{VOC}}$ ) for these compounds were estimated to be $\sim 22,8$ and $40 \%$, respectively (during experiment 6), accounting for a significant fraction of mass within the system.

As the oxidation process progressed a multitude of organic species containing one or more different types of functional group were formed within the chamber, many of which were detected by CIR-TOF-MS (see Table 4). Figure 10c gives the concentration-time profiles for three such compounds formed following ring cleavage, the multifunctional tertiary products 2-methyl4-oxo-pent-2-enoic acid $\left(\mathrm{CO}\left(\mathrm{CH}_{3}\right) \mathrm{CH}=\mathrm{C}\left(\mathrm{CH}_{3}\right) \mathrm{COOH}\right)$ and acetyl-2-methyl-oxirane-2-carbaldehyde $\left(\mathrm{CH}_{3} \mathrm{C}(\mathrm{O}) \mathrm{CH}(-\mathrm{O}\right.$ ) $\left(\mathrm{CH}_{3}\right) \mathrm{CHO}$ ) (measured together at $\mathrm{m} / z, 129$ ) and hydroxy acetone $(\mathrm{m} / \mathrm{z}, 75)$. Collision energy studies have shown that 2-methyl-4-oxo-pent-2-enoic acid also undergoes a small amount of dehydration following proton transfer to yield a fragment of $m / z$ 111. Also given in Fig. 10c is the signal measured at $m / z 43$, a generic marker for carbonyls using the PTR-MS technique (Blake et al., 2006). All such later stage oxidation products displayed similar behaviour, a steady rise to plateau roughly coinciding with peak aerosol mass. Strong signals corresponding to nitrated VOCs (even $\mathrm{m} / \mathrm{z}$ number and low mass excess) were also measured further down the oxidation chain; these included peroxy acetyl nitrate (PAN) (fragment ion at $m / z, 46$, Hansel and Wisthaler, 2000) and two unidentified compounds of $m / z, 96$ and 136 (given later in Fig. 14). Signals corresponding to pyruvic acid $(\mathrm{m} / \mathrm{z}$ 89) and formaldehyde $(\mathrm{m} / \mathrm{z} 31)$, two potential monomer units for the TMB oligomer (Kalberer et al., 2004), were also measured in all experiments.

Further inspection of Table 4 shows that a number of other simple organic acids were observed in the gas phase, including hydroxy acetic acid $(\mathrm{m} / \mathrm{z}, 77)$, acetic acid $(\mathrm{m} / \mathrm{z}, 61)$ and formic acid $(\mathrm{m} / \mathrm{z} 47)$. As shown in Fig. 10d and Table 4 , the various late stage acids appeared in the chamber $\sim 20-200 \mathrm{~min}$ after lights on. Concentrations of hydroxy acetic acid rose steadily to a peak of around $30 \mathrm{ppbV}$ at 400 min during experiment $6\left(\mathrm{Y}_{\mathrm{VOC}}=6 \%\right)$, followed by a steady decline due to gas phase oxidation and potential loss to the aerosol. Both formic and acetic acid levels continued to rise throughout experiment 6 as the system became more oxidised, with concentrations eventually reaching 100 $120 \mathrm{ppbV}$ ( $\mathrm{Y}_{\mathrm{VOC}} \sim 11$ and 16\%, respectively). It should be noted that during "blank" experiments (no precursor VOC), a small amount of both formic and acetic acid were observed in the gas phase following liberation from the illuminated chamber walls. After $\sim 7 \mathrm{~h}$ of blank experiment $\sim 10 \mathrm{ppbV}$ of both formic and acetic acid was measured, hence concentrations quoted here constitute an upper limit and should be considered with care. However, Fisseha and colleagues (Fisseha et al., 2004) recently recorded similar gas phase concentrations of formic acid during TMB photooxidation $(\sim 80 \mathrm{ppbV}$ after $9 \mathrm{~h}$ ), along with significant levels within the aerosol ( $\sim 15 \mu \mathrm{g} \mathrm{m}^{-3}$ at peak aerosol concentration). They presented lower acetic acid concentrations than were measured here $(\sim 30 \mathrm{ppbV})$, with differences most likely explained by potential contribution to mass channel 61 from other species in the CIR-TOF-MS measurements (primarily fragment ions derived from other organic acids).

\subsubsection{Variation of the $\mathrm{VOC} / \mathrm{NO}_{\mathrm{x}}$ ratio under high $\mathrm{NO}_{\mathrm{x}}$ con- ditions}

When $\mathrm{NO}_{\mathrm{x}}$ was initially introduced only in the form of $\mathrm{NO}$ (experiment 2), the distribution and variety of ions within the mass spectrum and their concentration-time profiles were generally very similar to those of other experiments with initial $\mathrm{VOC} / \mathrm{NO}_{\mathrm{x}} \sim 2: 1$. The main exception to this was a delay in the appearance times of most compounds, corresponding to the time required to liberate $\mathrm{HONO}$ and $\mathrm{NO}_{2}$ from reactions on the chamber walls and hence for the radical chemistry to initiate. Also, the oxidation products reached higher peak concentrations due to the enhanced level of starting material, but ultimately achieved similar yields to the other experiments of $\mathrm{VOC} / \mathrm{NO}_{\mathrm{x}} \sim 2: 1$ (see Table A2 in the supplementary material).

The behaviour of the VOC component of the chamber differed more significantly when the $\mathrm{VOC} / \mathrm{NO}_{\mathrm{x}}$ ratio was reversed to a value of $\sim 1: 2$. The most obvious point of note was that despite generally exhibiting similar temporal behaviour to other high $\mathrm{NO}_{\mathrm{x}}$ experiments, the oxidation products of this system took significantly longer to appear and achieve peak concentrations.

\subsubsection{Variation of the $\mathrm{VOC} / \mathrm{NO}_{\mathrm{x}}$ ratio, low $\mathrm{NO}_{\mathrm{x}}$ conditions}

The low $\mathrm{NO}_{\mathrm{x}}$ experiments conducted here (i.e. experiments 5 and $7, \mathrm{VOC} / \mathrm{NO}_{\mathrm{x}} \sim 16: 1$ ) were significantly different to the high $\mathrm{NO}_{\mathrm{x}}$ experiments not only in terms of the aerosol phase, but also in terms of the composition and temporal behaviour of the gas phase VOC matrix. Along with exhibiting significantly earlier nucleation events, due to the presence of the HONO radical source, experiments 5 and 7 were also characterised by the much earlier appearance of all gas phase VOC oxidation products when compared to other experiments, as can be seen in Table 4. Figures 11 and 12 show that, once present in the chamber, the TMB oxidation products exhibited significantly different temporal behaviour under low $\mathrm{NO}_{\mathrm{x}}$ conditions when compared to other experiments. The majority of primary oxidation products were observed to rise more gradually from "lights on" to a concentration plateau, rather than a distinct peak. Consequently, the point of maximum concentration often occurred later than in other experiments, e.g. methyl glyoxal $(\mathrm{m} / \mathrm{z}, 73)$ and the $\mathrm{m} / \mathrm{z} 113 \mathrm{com}-$ pounds reached maxima around 50-70 min later than in experiment 6 , achieving $\sim 50$ and $20 \mathrm{ppbV}$, respectively. Correspondingly the later stage oxidation products also presented different temporal profiles. As seen in Fig. 10c and d, the tertiary products presented more linear growth profiles early 


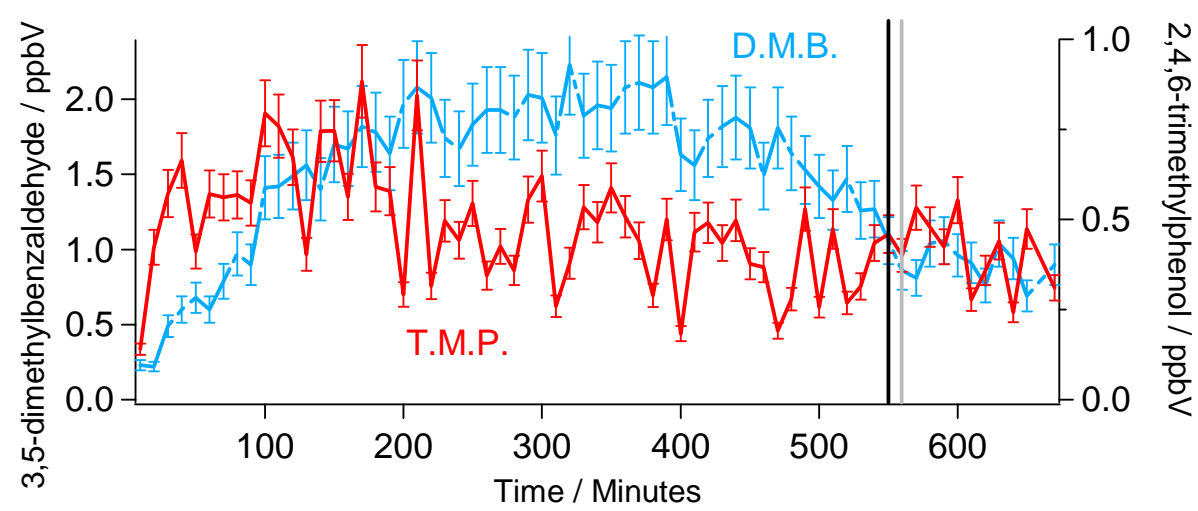

Fig. 11. Temporal evolution of 2,4,6-trimethylphenol and 3,5-dimethylbenzaldehyde during low $\mathrm{NO}_{\mathrm{x}}$ experiment 7 . The black vertical line indicates the start of the "dark phase" and the grey vertical line indicates the NO injection time.
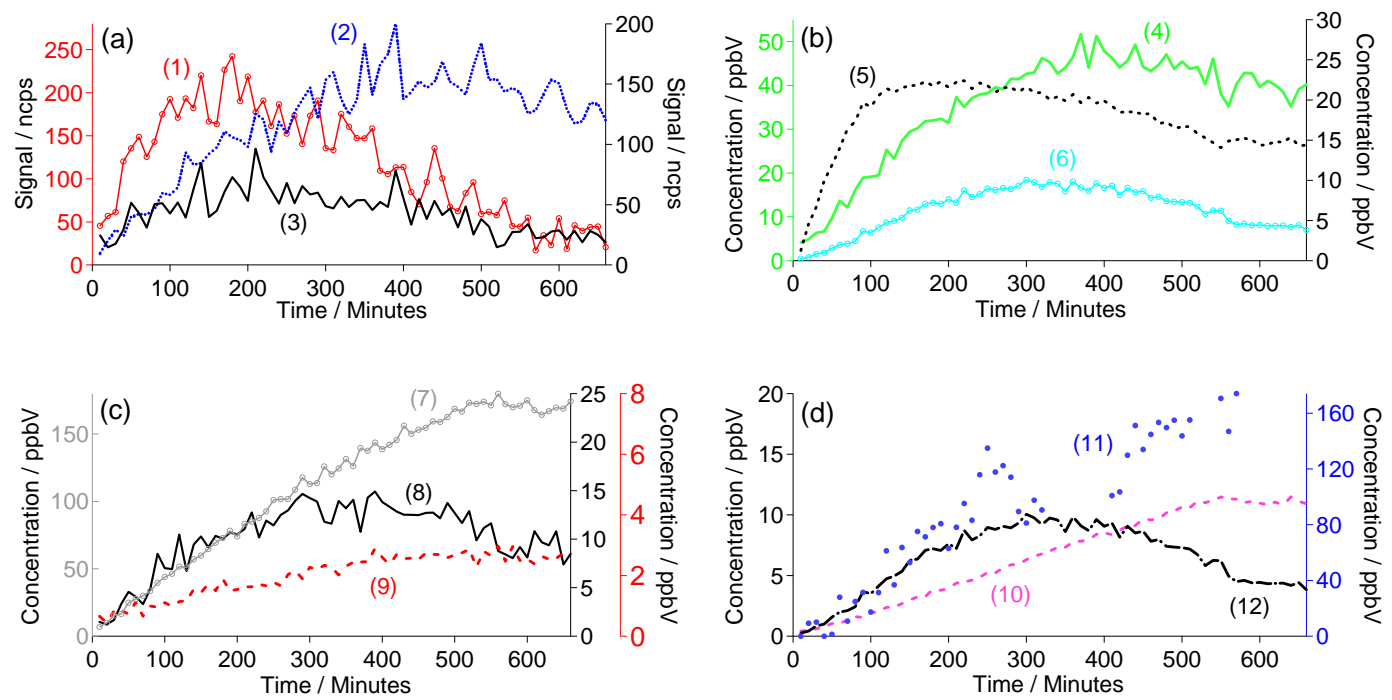

Fig. 12. Temporal evolution of a selection of important VOCs measured during the photooxidation of 1,3,5-TMB in experiment 7 (VOC/NO $\mathrm{NO}_{\mathrm{x}} \sim 17: 1$ ). Compound numbering is the same as that used in the caption for Fig. 10. In (a) the signal of the $\mathrm{O}_{2}$-bridged diol (3) is given on the right axis, in (b) the concentration of methyl glyoxal (4) is given on the left axis and in (d) the concentration of hydroxy acetic acid (10) is given on the left axis. Chamber lights were switched off for the "dark phase" at 550 min followed by NO injection (see text for details).

in the experiment, being produced more rapidly due to the presence of an $\mathrm{OH}$ source. The "start-up" lag seen in other experiments, corresponding to the time required to establish the $\mathrm{OH}$ cycle was absent. During the low $\mathrm{NO}_{\mathrm{x}}$ experiments, the tertiary products were often characterised by linear profiles due to a roughly constant level of oxidant.

Most VOC yields (determined for the calibrated compounds) during the low $\mathrm{NO}_{\mathrm{x}}$ experiments were similar in magnitude to those of the high $\mathrm{NO}_{\mathrm{x}}$ experiments of $\mathrm{VOC} / \mathrm{NO}_{\mathrm{x}} \sim 2: 1$, with some significant exceptions. Hydroxy acetic acid, acetic acid and formic acid yields obtained during the low $\mathrm{NO}_{\mathrm{x}}$ experiments were on average significantly larger than those of the high $\mathrm{NO}_{\mathrm{x}}$ experiments, i.e. 14, 33 and $49 \%$ compared to 4,15 and $13 \%$, respectively. Yields for methyl glyoxal and the $\mathrm{m} / \mathrm{z} 113$ compounds were slightly lower under low $\mathrm{NO}_{\mathrm{x}}$ conditions, being $\sim 20$ and 30\%, respectively.

\subsubsection{Elucidating the gas phase oxidation mechanisms}

In order to elucidate the chemical mechanism underlying the TMB oxidation system, at the conclusion of certain experiments chamber lights were switched off and the total chamber ozone was titrated from the system with the addition of excess NO to the matrix. During experiments 6 and 7 the chamber lights were switched off at 460 and 550 minutes, respectively, with the addition of NO some 70 and $10 \mathrm{~min}$ later. Approximately $200 \mathrm{ppbV} \mathrm{NO}$ was introduced into the 
chamber during experiment 6 and approximately $100 \mathrm{ppbV}$ NO was introduced during experiment 9. The effect of this "dark phase" on the inorganic components of the matrix and the VOCs for experiments 6 and 7 can be seen in Fig. 1a and d, Figs. 10 and 12.

During the dark phase the photochemically driven pathways became "switched off" as photolysis and $\mathrm{OH}$ production from both ozone and HONO ceased. Also, as the chamber ozone was titrated away, chemistry occurring via ozonolysis reactions became negligible. Consequently, the system chemistry was switched from a regime where reactions of $\mathrm{RO}_{2}$ were controlled by $\mathrm{OH}$ and $\mathrm{HO}_{2}$ to one in which the majority of $\mathrm{RO}_{2}$ species were removed from the system following reaction with the injected NO. This resulted in a "burst" in production of $\mathrm{NO}_{2}$ and, to a minor extent, nitrogenated and carbonyl compounds. The major fraction of the additional $\mathrm{NO}_{2}$ measured during the dark phase clearly results from the $\mathrm{NO}+\mathrm{O}_{3} \rightarrow \mathrm{NO}_{2}+\mathrm{O}_{2}$ reaction. However, it is likely that $\mathrm{NO}_{2}$ will also be liberated from the thermal decomposition of reservoir, PAN type compounds and initially from $\mathrm{RO}_{2}+$ NO reactions. Manipulating the chemistry in this manner and observing the resultant effect on the VOC evolution provides insight into the chemistry involved.

The concentration-time profile of the peroxide bicyclic ketone, seen in Fig. 10a, began to fall significantly when chamber lights were switched off, suggesting that its production must result from reactions involving $\mathrm{RO}_{2}, \mathrm{HO}_{2}$ and $\mathrm{OH}$ as detailed in Fig. 6. As the photolytic formation of radicals was "switched off" under dark phase conditions, production of the bicyclic ketone was no longer possible and its chamber concentration began to decay due either to the instability of this species and/or via its reaction with $\mathrm{NO}_{3}$. Conversely during the dark phase, the fall in concentration of the bicyclic nitrate was arrested before levelling off to plateau as its major loss processes (i.e. photolysis and reaction with $\mathrm{OH}$ ) were switched off.

Following the addition of NO to the chamber a significant increase in the signal measured at $\mathrm{m} / \mathrm{z} 113$ was observed. This response is essentially a consequence of the parent $\mathrm{O}_{2}$-bridged species decomposing through ring opening pathways to yield various (isobaric) oxygenated products. For example, following the photooxidation mechanism outlined in Fig. 6, it is likely that the peroxide bicyclic ketone decays via several intermediate steps to 3,5-dimethyl-5(2H)2 -furanone, verifying the significant contribution made from further reaction of the bicyclic ketone to the signal measured at $m / z 113$.

The findings presented here highlight the importance of reaction routes involving both the bicyclic ketone and nitrate compounds during the early stages of the experiment in the production of other potentially crucial SOA forming oxidation products (see Sect. 3.9).

\subsection{Principal Component Analysis}

As noted by Baltensperger et al. (2005) the VOCs observed in the oxidation of TMB can be separated into several distinct categories according to their temporal profiles. In order to better identify trends within the time series data, a Principal Component Analysis (PCA, Næs and Martens, 1988) was carried out for each experiment. PCA is an exploratory data analysis technique that will summarise correlated time behaviour of certain masses into a set of principal components. Each principal component consists of a pair of vectors: the scores vector (depicting time related behaviour) and the loadings vector (representing how strongly this behaviour is represented on each of the masses). The PCA algorithm will first find the strongest collective time trend in the data and its associated mass spectrum, followed by the second strongest and so on. Consequently, it may be possible to represent key trends in the whole experiment with only a few principal components. Ultimately the PCA can be used to identify which compounds are related in the oxidation system.

Generally during each of the PC analyses the majority of the temporal variability within the VOC data was captured by the first three principal components ( $\mathrm{PC} 1$ accounted for $\sim 75-95 \%$ of the variance, PC2 $4-22 \%$ and PC3 only $\sim 0.6-1.5 \%$ ). As an example of the high $\mathrm{NO}_{\mathrm{x}}$ data, the scores and loading plots obtained from a PCA conducted for experiment 6 are given in Fig. 13a. The scores plots generated for $\mathrm{PC} 1$ for each high $\mathrm{NO}_{\mathrm{x}}$ experiment exhibited roughly the same pattern, i.e. a sigmoidal rise to peak and plateau. The most significant masses comprising the corresponding loadings vector were $\mathrm{m} / \mathrm{z} 43$ (carbonyl marker), 46 (PAN marker), 61 (acetic acid), 73 (methyl glyoxal), 77 (hydroxyl acetic acid), 87 (unidentified), 111 (3-methyl5-methylidiene-5(2H)-2-furanone) and 185 (the $\mathrm{O}_{2}$-bridged ketone). All of these masses (except $\mathrm{m} / \mathrm{z}$ 185) constitute secondary or tertiary oxidation products of the TMB system (although methyl glyoxal also constitutes a primary product). The PAN and acetic acid signals were the greatest contributors towards the first principal component in all high $\mathrm{NO}_{\mathrm{x}}$ experiments, suggesting a strong contribution to the chamber matrix from these compounds.

The scores generated for PC2 were characterised by a rapid rise to peak followed by a similarly steep decay to steady state. The most significant corresponding loadings were $\mathrm{m} / \mathrm{z} 45$ (methyl glyoxal fragment), 73 (methyl glyoxal), 85 ( $\mathrm{m} / z 113$ fragment), 113 (isobaric furanone and $\delta$ dicarbonyl ring opening products), 125 (bicyclic fragment), 135 (3,5-dimethyl benzaldehyde), 109, 214 and 232 (bicyclic nitrate). These compounds constitute the primary oxidation products of the TMB oxidation system. The $\mathrm{m} / \mathrm{z}, 73$ and 113 signals were the greatest contributors towards the second principal component in all high $\mathrm{NO}_{\mathrm{x}}$ experiments, demonstrating the importance of these compounds early within the chamber atmosphere. PC3 accounts for very little of the variance within all experiments, only $\sim 1 \%$ and is composed 

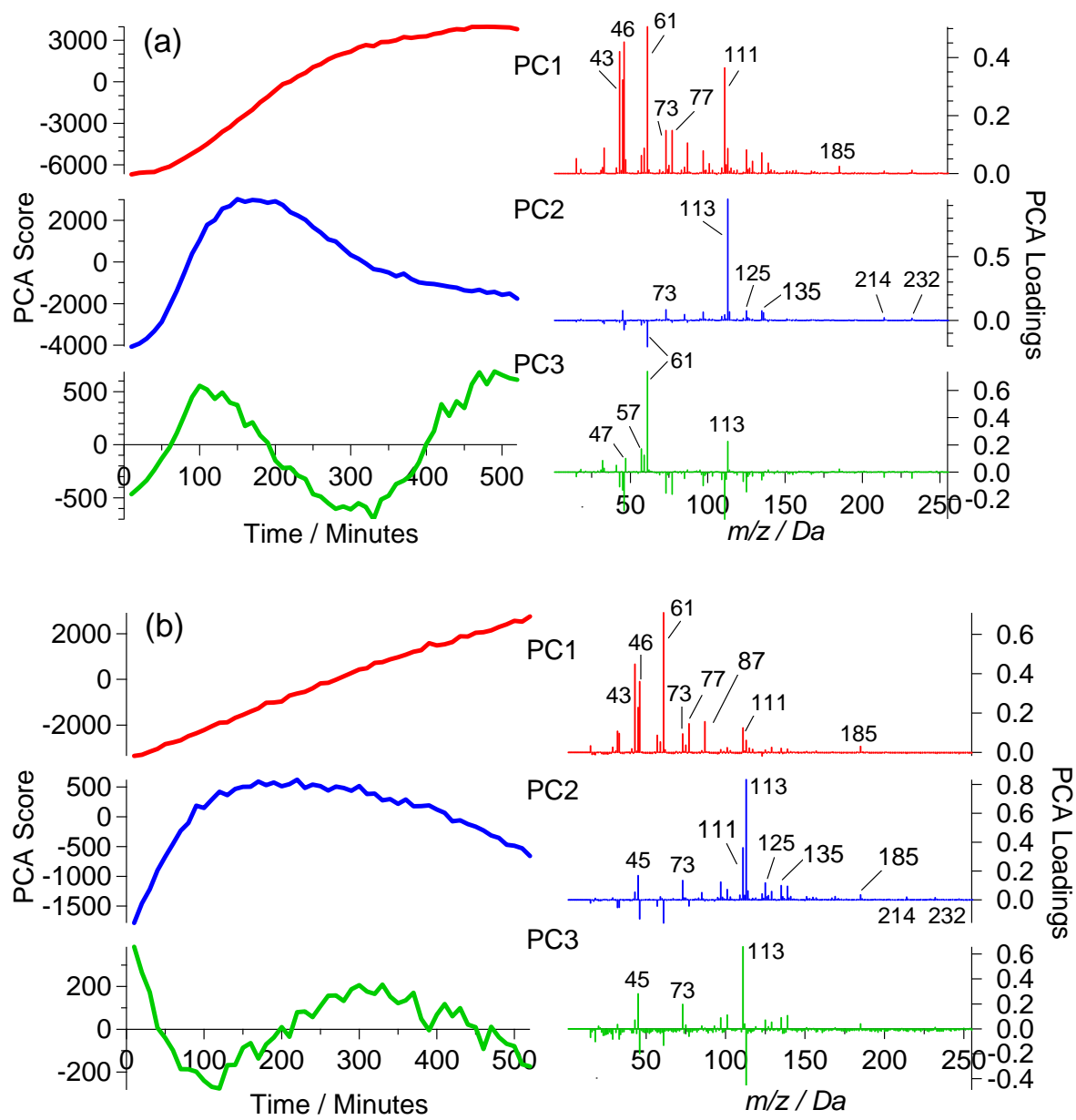

Fig. 13. Principal component analysis conducted on VOC data for (a) experiment 6 (high $\mathrm{NO}_{\mathrm{x}}$, $\left.\mathrm{VOC}_{\mathrm{NO}} \sim 2: 1\right)$ and (b) experiment 7 (low $\mathrm{NO}_{\mathrm{x}}, \mathrm{VOC} / \mathrm{NO}_{\mathrm{x}} \sim 17: 1$ ). Percentage variance captured: $\mathrm{PC} 1=78.0 \%, \mathrm{PC} 2=19.7 \%$ and $\mathrm{PC} 3=1.9 \%$ for experiment 6 and $\mathrm{PC} 1=90.0 \%$, $\mathrm{PC} 2=8.0 \%$ and $\mathrm{PC} 3=0.6 \%$ for experiment 7 .

mainly of three significant loadings, which correspond to masses 57, 61 and 113 .

The PCA for low $\mathrm{NO}_{\mathrm{x}}$ experiment 7 is shown in Fig. 13b. Comparison of the scores plots with those of experiment 6 (Fig. 13a) demonstrates the dramatic differences in the temporal behavior of the oxidation products, with no evidence of an incubation period in the VOC chemistry, i.e. the primary, secondary and tertiary products of oxidation appear in the system early on in the experiment. PC1 for the low $\mathrm{NO}_{\mathrm{x}}$ system is primarily composed of the same compounds as in the high $\mathrm{NO}_{\mathrm{x}}$ system, but with a different distribution of abundances. Under low $\mathrm{NO}_{\mathrm{x}}$ conditions $\mathrm{m} / \mathrm{z}$ 45, 46, 73, and 111 all show significantly lower contributions to overall secondary products, although $\mathrm{m} / z 61$ remains the greatest contributor, suggesting a more dominant role for acetic acid in the absence of $\mathrm{NO}_{\mathrm{x}}$. In contrast to this, $\mathrm{PC} 2$ is composed of a slightly different set of masses with distinctly different abundances. Masses 45, 73, 97 (unidentified), 125, 135 and particularly 111 all give stronger contributions to the overall signal than in the high $\mathrm{NO}_{\mathrm{x}}$ experiments. Furthermore, the second principal component also contains contributions from masses 101 (unidentified), 129 (organic acid), 139 (potential organic peroxide), $169\left(\mathrm{O}_{2}\right.$-bridged diol) and 185, contrary to the high $\mathrm{NO}_{\mathrm{x}}$ system. These findings suggest that although ultimately the same end stage oxidation products are reached, during the early stages of the low $\mathrm{NO}_{\mathrm{x}}$ experiments (i.e. approximately around the time of nucleation), the system chemistry is somewhat different, generating an organic gas phase matrix that is more strongly dominated by the primary $\mathrm{O}_{2}$-bridged bicyclics, methyl glyoxal and the $\mathrm{m} / \mathrm{z} 113$ compounds. This finding implicates therefore, that such species may play some role in the formation of aromatic SOA.

3.9 Identification of compounds contributing to SOA formation and growth

Although a large fraction of SOA mass remains to be identified, recent studies into the composition of aerosol 
formed from aromatic compounds has highlighted the presence of a discrete set of organic species originating directly from gas phase oxidation of the precursor. Of these compounds previously identified within the aerosol, several were measured (or their analogous counterparts were measured) in the gas phase during the present study, including 3,5dimethylbenzaldehyde (Hamilton et al., 2003) from the ring retaining route, several of the isobaric $\mathrm{m} / \mathrm{z} 113$ furanones (Forstner et al., 1997; Hamilton et al., 2003) and methyl glyoxal (Kalberer et al., 2004) from the ring opening route, along with the later stage decay products hydroxy acetone, glycoaldehyde (Cocker III et al., 2001), formic acid and acetic acid (Fisseha et al., 2004).

For the gas phase species to take part in the SOA formation process, first of all their presence in the chamber must coincide with or precede the onset of nucleation. By the time of nucleation in each high $\mathrm{NO}_{\mathrm{x}}$ experiment, virtually all of the measured organic species had appeared within the chamber and hence (where possible) were available for partitioning. In contrast, a more select group of only thirteen spectral features were present in the mass spectra of both low $\mathrm{NO}_{\mathrm{x}}$ experiments prior to nucleation, and hence available to partition to the aerosol. This result implies that the early stage aerosol in the low $\mathrm{NO}_{\mathrm{x}}$ systems may be compositionally less diverse.

Several of the "early" compounds of the low $\mathrm{NO}_{\mathrm{x}}$ system were observed within the first few minutes of experiment: these include the $\mathrm{O}_{2}$-bridged nitrate (at $\mathrm{m} / z, 232,214$ and 109), $\mathrm{O}_{2}$-bridged diol $(\mathrm{m} / \mathrm{z} 169)$, (potential) fragment ion of the $\mathrm{O}_{2}$-bridged compounds $(\mathrm{m} / \mathrm{z}, 125)$, methyl glyoxal $(\mathrm{m} / \mathrm{z}$ 73 ) and the $m / z, 113$ ring opening compounds. Other notable cases of early appearance include the $\mathrm{O}_{2}$-bridged ketone, 3,5dimethyl benzaldehyde, hydroxy acetic acid, acetic acid and the carbonyl marker $(\mathrm{m} / \mathrm{z}, 185,135,77,61$ and 43 , respectively). As some organic compounds are not easily ionised using the proton transfer reaction technique (e.g. peroxides) and as detection limits may have excluded some compounds, it is not possible at present to conclusively assign the nucleating species. However, with only the above listed compounds measured before nucleation in every experiment, it is possible that at least some of these species will be of importance in the SOA formation process.

The appearance times of the majority of the oxidation products observed during low $\mathrm{NO}_{\mathrm{x}}$ experiment 5 were slightly greater than in the corresponding low $\mathrm{NO}_{\mathrm{x}}$ experiment 7 , as was the time of the nucleation event. Although nucleation during experiment 7 was influenced by the presence of the inorganic seed particles, the slightly higher $[\mathrm{OH}]$ (resulting from minor inaccuracies in the HONO input magnitude between experiments) would have facilitated faster oxidation and therefore earlier SOA formation. A similar trend was also noted when the $\mathrm{VOC} / \mathrm{NO}_{\mathrm{x}}$ ratio was set to $\sim 1: 2$. Here the appearance times of most of the TMB oxidation products were significantly delayed with respect to all other experiments. For example, the $m / z, 113$ compounds appeared $\sim 30$ min later, and several of the signals observed in mass channels representative of the primary bicyclic compounds (e.g. $m / z 214$ and 125) up to a full hour later than in experiment 6 (see Table 4 for further comparison). Subsequently many compounds reached their peak concentrations later than in other experiments, for example methyl glyoxal, the $m / z, 113$ oxygenates and the $\mathrm{O}_{2}$-bridged nitrate, reached peak concentrations 170,80 and 80 minutes later than in experiment 6 , respectively. This delay and subsequent shift in concentration peak coincided with the delay in nucleation described earlier, further implicating the importance of such compounds in aerosol formation and growth.

As noted above, the low $\mathrm{NO}_{\mathrm{x}}$ system was characterised by an enhancement in the yields for certain gas phase species, including several organic acids. Hydroxy acetic acid, acetic acid and formic acid yields during the low $\mathrm{NO}_{\mathrm{x}}$ experiments were on average $\sim 3.5,2.2$ and 3.7 times larger than during the high $\mathrm{NO}_{\mathrm{x}}$ experiments of $\mathrm{VOC} / \mathrm{NO}_{\mathrm{x}} \sim 2: 1$ and 1.5, 2.8 and 6.8 times larger than during high $\mathrm{NO}_{\mathrm{x}}$ experiment 3 of $\mathrm{VOC} / \mathrm{NO}_{\mathrm{x}} \sim 1: 2$. As experiment 3 was conducted with the same initial TMB concentration as the two low $\mathrm{NO}_{\mathrm{x}}$ experiments, concentration-dependent yield artefacts suggested by some authors can be ruled out ( $\mathrm{Ng}$ et al., 2007).

Considering that these organic acids were available in the gas phase matrix from early on in all experiments, it is possible that their enhanced gas phase yields were at least in some part responsible for the observed increase in aerosol yields which were obtained under low $\mathrm{NO}_{x}$ conditions. Indeed, various recent reports have highlighted the importance of organic acids in the composition of SOA. For example, Fisseha et al. (2004) have shown that around the point of maximum aerosol number density, organic acids comprised as much as $43 \%$ of aerosol mass.

As well as simply being detected in the aerosol phase, evidence has come to light implicating that such organic acids may become incorporated into polymer-like structures found within SOA (Gross et al., 2006; Kalberer et al., 2006). Other findings published recently by various authors indicate that an acidic environment is important (but not necessarily a prerequisite) for the formation of such polymer species via various mechanistic pathways (Jang and Kamens, 2001; Czoschke et al., 2003; Limbeck et al., 2003; Gao et al., 2004; Tolocka et al., 2004; Northcross and Jang, 2007; Surratt et al., 2007; Verheggen et al., 2007). However as noted above, in the current study no distinct difference in aerosol yield was observed between the homogeneous nucleation experiment (5) and the acid-seeded experiment (7). It would seem reasonable to assume therefore that if enough $\mathrm{SO}_{2}$ was present to cause an acid seed effect and that the observed enhancement in aerosol yield is related to the enhancement in yields of the gaseous organic acid, then the levels of acids produced under low $\mathrm{NO}_{\mathrm{x}}$ conditions were large enough to facilitate any acid-catalysed polymerisation without the need for the inorganic acid surface. Alternatively, the organic acids may contribute to SOA mass without involvement in additional 
acid-catalysed polymerisation. It is worth noting that in the case of formic and acetic acid, some small fraction of that measured within the gas phase may have originated from the chamber walls ( $\sim 10 \%$ or less), hence care is required when assessing their potential contributions towards TMBSOA formation.

With no calibration method or reliable kinetic information available for the primary bicyclic compounds, it is not possible at present to derive their absolute concentrations or yields. However, pseudo yields may be derived by applying the CIR-TOF-MS sensitivity for a structurally similar compound, and in this instance $m$-tolualdehyde was employed. Regardless of the absolute values obtained, a ratio of the yields for the low versus high $\mathrm{NO}_{\mathrm{x}}$ experiments can be used to infer the importance of the primary bicyclic species in the SOA formation/growth process. Using data from experiments 6 and 7, the ratio (experiment 7:experiment 6) of pseudo yields obtained for the $\mathrm{O}_{2}$-bridged nitrate was 1.36 , suggesting a small enhancement in the production of this compound under low $\mathrm{NO}_{\mathrm{x}}$ conditions. The corresponding ratios for $m / z 169$ and 185 were 4.83 and 2.89 , respectively, indicating much stronger production of the $\mathrm{O}_{2}$-bridged diol and the $\mathrm{O}_{2}$-bridged ketone in the absence of $\mathrm{NO}_{\mathrm{x}}$. Similar yield ratios were obtained for the measured $\mathrm{O}_{2}$-bridged compounds when comparing high and low $\mathrm{NO}_{\mathrm{x}}$ experiments with the same starting concentration of TMB (i.e. experiments 3 and 7 , respectively), hence again any concentrationdependent yield artefacts can be ruled out.

As with the organic acids, the increased yield of the $\mathrm{O}_{2}$ bridged compounds could explain the enhanced SOA yield observed under low $\mathrm{NO}_{\mathrm{x}}$ conditions, particularly when supported by evidence of their appearance in the chamber prior to nucleation in each experiment. Furthermore, modelling studies by Stroud et al. (2004) and Johnson et al. (2005) have shown that the analogous $\mathrm{O}_{2}$-bridged nitrate (as well as other multi-functional $\mathrm{O}_{2}$-bridged products) in the toluene system and the $\mathrm{O}_{2}$-bridged ketone (as well as other 5 and 6 membered ring compounds bearing nitrate and hydroperoxide functionalities) in the TMB system, are liable to undergo partitioning to the aerosol phase and make a significant contribution to simulated SOA mass.

Using the methodology applied by $\mathrm{Ng}$ et al. (2006) it is possible to obtain further information regarding which species contribute to SOA growth via close inspection of the VOC time series profiles. The concentration peaks of the $\mathrm{O}_{2}$ bridged nitrate, the unidentified organic nitrate at $\mathrm{m} / \mathrm{z} 136$ and the isobaric $\mathrm{m} / \mathrm{z} 113$ oxygenates roughly coincide with the nucleation event. Indeed, it was observed that a shift in the time at which these compounds achieved their respective concentration peaks, was matched by a corresponding shift in the time of nucleation. Subsequently, the period over which these species were "lost" from the gas phase was coincident with the period over which the aerosol was observed to grow. Plotting the mass of these compounds consumed (or "lost") after their concentration peak versus SOA mass "produced" (up to the point of maximum mass) gives a strong correlation. An example of this is given in Fig. 14a and b for the organic nitrate of $m / z 136$.

The correlation plots of $\mathrm{O}_{2}$-bridged nitrate for experiments conducted under high $\mathrm{NO}_{\mathrm{x}}$ conditions are similar to those conducted under low $\mathrm{NO}_{\mathrm{x}}$ (plots for experiments 6 and 7 , given in Fig. 15a and b). The correlation between mass lost and SOA mass produced indicates that the $\mathrm{O}_{2}$-bridged nitrate contributes to SOA growth, either by direct partitioning or via further reaction generating condensable products. A steeper line fit during the low $\mathrm{NO}_{\mathrm{x}}$ experiment suggests more rapid SOA growth with respect to expenditure of the $\mathrm{O}_{2}$-bridged nitrate in the absence of $\mathrm{NO}_{\mathrm{x}}$ (see Fig. 15 for line fit coefficients). The presence of a non-zero intercept on the ordinate axis $\left(\sim 16-19 \mu \mathrm{g} \mathrm{m}^{-3}\right)$ implies that a given amount of SOA mass had formed before any contribution to SOA growth from the $\mathrm{O}_{2}$-bridged nitrate.

Correlation plots for loss of the organic nitrate at $m / z, 136$ (not shown) and the $m / z 113$ compounds under low $\mathrm{NO}_{\mathrm{x}}$ conditions (Fig. 15d) are very similar to those of the bicyclic nitrate. Hence, similarly under low $\mathrm{NO}_{\mathrm{x}}$ conditions it appears that the organic nitrate of $\mathrm{m} / \mathrm{z} 136$ and one or more of the compounds measured at $\mathrm{m} / \mathrm{z} 113$ contribute to SOA growth once SOA has formed. As shown in Figs. $14 \mathrm{~b}$ and $15 \mathrm{c}$ for high $\mathrm{NO}_{\mathrm{x}}$ experiment 6, the quantities of $\mathrm{m} / z, 136$ and 113 lost from the gas phase exhibited yet higher correlation with the growth of SOA mass $\left(r^{2}=0.94\right.$ and 0.97 , respectively), providing further strong evidence that these species play an important role in TMB-SOA growth. However, as with the bicyclic nitrate the steepness of this correlation was greater under low $\mathrm{NO}_{\mathrm{x}}$ conditions.

Interestingly, for the $\mathrm{m} / \mathrm{z}, 136$ and 113 compounds, under high $\mathrm{NO}_{\mathrm{x}}$ conditions there exists a small non-zero intercept on the abscissa, suggesting that either no or very little SOA mass had formed prior to loss of these compounds from the gas phase. This result suggests that as well as contributing to SOA growth, the organic nitrate of $\mathrm{m} / z, 136$ and the compounds of $\mathrm{m} / z 113$ play some role in particle formation under high $\mathrm{NO}_{\mathrm{x}}$ conditions.

It would seem from the evidence presented here that the $\mathrm{O}_{2}$-bridged nitrate and $\mathrm{m} / z .113$ compounds contribute towards SOA growth, along with compounds such as the unidentified organic nitrate $(\mathrm{m} / \mathrm{z} 136)$, the $\mathrm{O}_{2}$-bridged diol and the lower molecular mass organic acids. However, evidence obtained from the low $\mathrm{NO}_{\mathrm{x}}$ experiments suggests that the presence of other species is required to initiate nucleation. From the discussion presented here two likely candidates for the role of "nucleating species" are:

1. $\mathrm{O}_{2}$-bridged ketone. The bicyclic ketone is present in the gas phase before nucleation in all experiments and has a temporal profile that grows in line with SOA mass. Furthermore, the higher gas phase yield for the bicyclic ketone under low $\mathrm{NO}_{\mathrm{x}}$ conditions is matched by an ultimately higher aerosol yield. This suggestion 


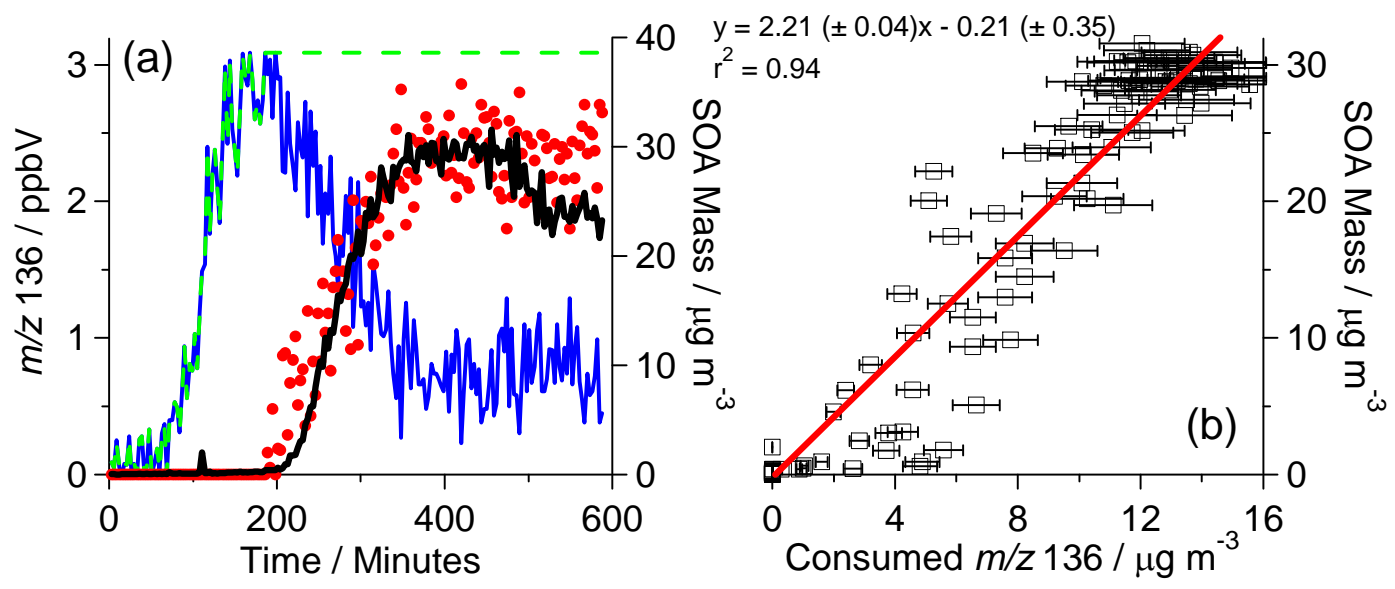

Fig. 14. (a) Temporal evolution of the unidentified organic nitrate of $m / z, 136$ (solid blue line) during experiment 6 (high $\mathrm{NO}_{\mathrm{x}}$ ). Plot includes total amount of $\mathrm{m} / \mathrm{z}, 136$ formed (dashed green line) and total amount lost (red circles). Also included is an overlaid profile of SOA mass (solid black line). (b) Correlation between $\mathrm{m} / \mathrm{z}, 136$ mass lost and SOA mass formed (up to the point of peak mass) for experiment 6 . Coefficients quoted \pm one standard deviation.
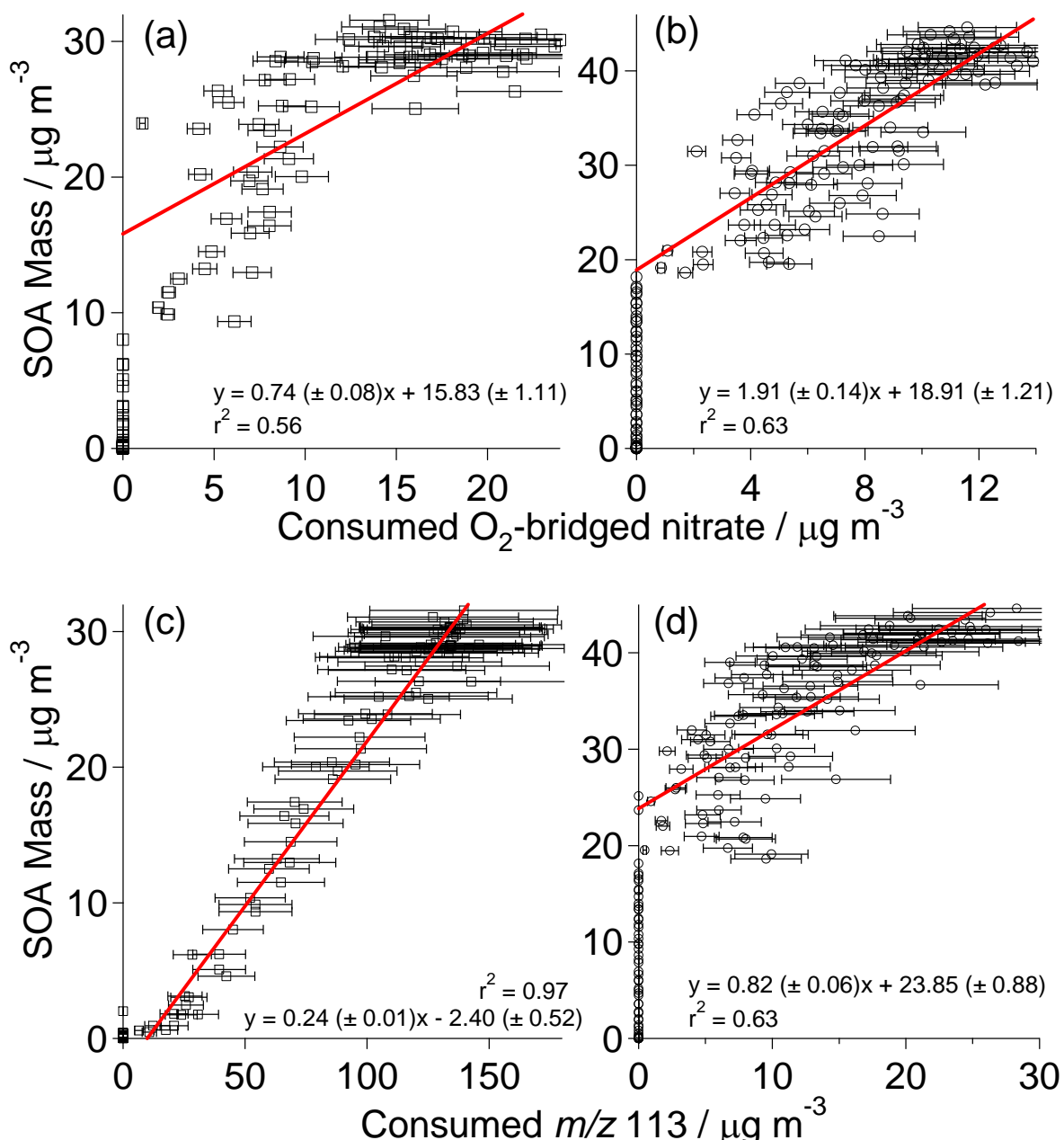

Fig. 15. Correlation between mass of VOC lost and mass of SOA formed (up to the point of peak mass), for the $\mathrm{O}_{2}$-bridged nitrate for (a) experiment $6\left(\right.$ high $\mathrm{NO}_{\mathrm{x}}$ ) and (b) experiment 7 (low $\mathrm{NO}_{\mathrm{x}}$ ) and for the $\mathrm{m} / z, 113$ ring opening compounds for (c) experiment 6 and (d) experiment 7. Correlation coefficients quoted one standard deviation. 
also supports modelling studies of Johnson et al. (2005), who propose significant partitioning of the $\mathrm{O}_{2}$-bridged ketone to the aerosol phase in their gas-aerosol coupled box model.

2. $\mathrm{O}_{2}$-bridged peroxide. As discussed in Sects. 6.3.3-6.3.5 there exists evidence from this work and from that of previous studies, that organic peroxides may play a significant role in SOA formation and growth. Considering the mechanism outlined in Fig. 6, the most dominant organic peroxide available early on in the chamber matrix is the $\mathrm{O}_{2}$-bridged peroxide (compound $\mathrm{M}$ ), formed from the parent $\mathrm{O}_{2}$-bridged peroxy radical $(\mathrm{K})$ reacting with $\mathrm{HO}_{2}$. No direct measurements of the bicyclic peroxide were made within this study; however from observations of the peroxy radical behaviour and from the partitioning theory of equation (E2) (see Fig. 3), it is highly likely that the $\mathrm{O}_{2}$-bridged peroxide would have been present in the chamber prior to nucleation in each experiment. We discuss the potential role of the $\mathrm{O}_{2}$ bridged peroxide in SOA formation and growth in more detail in a companion modelling paper, utilising comparison between the measurements described here and modelling results obtained from a chamber box model (Rickard et al., 2009).

\section{Conclusions}

The work presented here constitutes the most comprehensive set of gas phase measurements made to date describing the unexplored composition and evolution of the organic oxidation products of an anthropogenic SOA precursor. VOC measurements made by CIR-TOF-MS include gas phase oxidation products with the highest mass observed in aerosol simulation experiments so far. Furthermore, the high mass resolution available in TOF-MS has helped in the identification of these high mass compounds as certain primary bicyclic oxidation products (measurements of which have not previously been reported in the literature), which crucially give support to our current understanding of aromatic hydrocarbon oxidation. Moreover, compound appearance times, temporal behaviour and enhanced yields under low $\mathrm{NO}_{x}$ conditions (that correlate with enhanced SOA yields) imply a role for the oxygen-bridged species and certain organic acids in the growth of TMB-SOA.

Variation of the initial chamber $\mathrm{NO}_{x}$ conditions and timedependent SOA growth curves indicate a potential role for various other (multi-functional) gas phase organics in SOA growth, which appear at various stages in the oxidation chain. These include, 3,5-dimethylbenzaldehyde, nitrogenated compounds, furanone and dicarbonyl type species as well as simple low molecular weight organic acids. Along with methyl glyoxal, the $\mathrm{O}_{2}$-bridged ketone and the $m / z 113$ isobaric furanone and $\delta$-dicarbonyl ring opening products act as "mass conduits" through which a significant portion of mass transit occurs. Such strong markers could be used during gas phase measurements to "fingerprint" SOA formation episodes in the real atmosphere.

Acknowledgements. The authors would like to give thanks to Fraser Reich of Kore Technology, for his insightful advice regarding TOF-MS data analysis and to EPSRC and ACCENT for providing funds.

Edited by: R. Cohen

\section{References}

Atkinson, R.: Atmospheric chemistry of $\mathrm{VOCs}$ and $\mathrm{NO}_{\mathrm{x}}$, Atmos. Environ., 34, 2063-2101, 2000.

Baltensperger, U., Kalberer, M., Dommen, J., Paulsen, D., Alfarra, M. R., Coe, H., Fisseha, R., Gascho, A., Gysel, M., Nyeki, S., Sax, M., Steinbacher, M., Prevot, A. S. H., Sjogren, S., and Weingartner, E.: Secondary organic aerosols from anthropogenic and biogenic precursors, Faraday Discuss., 130, 265-278, 2005.

Blake, R. S., Whyte, C., Hughes, C. O., Ellis, A. M., and Monks, P. S.: Demonstration of Proton-Transfer Reaction Time-of-Flight Mass Spectrometry form Real-Time Analysis of Trace Volatile Organic Compounds, Anal. Chem., 76, 3841-3845, 2003.

Blake, R. S., Wyche, K. P., Ellis, A. M., and Monks, P. S.: Chemical ionization reaction time-of-flight mass spectrometry: Multireagent analysis for determination of trace gas composition, Int. J. Mass Spectrom., 254(1-2), 85-93, 2006.

Bloss, C., Wagner, V., Bonzanini, A., Jenkin, M. E., Wirtz, K., Martin-Reviejo, M., and Pilling, M. J.: Evaluation of detailed aromatic mechanisms (MCMv3 and MCMv3.1) against environmental chamber data, Atmos. Chem. Phys., 5, 623-639, 2005a, http://www.atmos-chem-phys.net/5/623/2005/.

Bloss, C., Wagner, V., Jenkin, M. E., Volkamer, R., Bloss, W. J., Lee, J. D., Heard, D. E., Wirtz, K., Martin-Reviejo, M., Rea, G., Wenger, J. C., and Pilling, M. J.: Developement of a detailed chemical mechanism (MCMv3.1) for the atmospheric oxidation of aromatic hydrocarbons, Atmos. Chem. Phys., 5, 641664, 2005b, http://www.atmos-chem-phys.net/5/641/2005/.

Bohn, B.: Formation of Peroxy Radicals from $\mathrm{OH}-\mathrm{Toluene}$ Adducts and $\mathrm{O}_{2}$, J. Phys. Chem. A, 105, 6092-6101, 2001.

Calvert, J. G., Atkinson, R., Becker, K. H., Kamens, R. M., Seinfeld, J., Wallington, T. J., and Yarwood, G.: The Mechanisms of Atmospheric Oxidation of Aromatic Hydrocarbons, Oxford University Press, 2002

Cocker III, D. R., Mader, B. T., Kalberer, M., Flagen, R. C., and Seinfeld, J. H.: The effect of water on gas-particle partitioning of secondary organic aerosol: II. $m$-xylene and 1,3,5trimethylbenzene photooxidation systems, Atmos. Environ., 35, 6073-6085, 2001.

Czoschke, N. M., Myoseon, J., and Kamens, R. M.: Effect of acidic seed on biogenic secondary organic aerosol growth, Atmos. Environ., 37, 4287-4299, 2003.

de Gouw, J. A., Goldan, P. D., Warneke, C., Kuster, W. C., Roberts, J. M., Marchewka, M., Bertman, S. B., Pszenny, A. A. P., and Keene, W. C.: Validation of proton transfer reaction-mass spectrometry (PTR-MS) measurements of gas-phase organic compounds in the atmosphere during the New England Air Quality 
Study (NEAQS) in 2002, J. Geophys. Res.-Atmos., 108(D21), 4682, doi:10.1029/2003JD003863, 2003.

Derwent, R. G., Jenkin, M. E., Passant, N. R., and Pilling, M. J.: Photochemical ozone creation potentials (POCPs) for different emission sources of organic compounds under European conditions estimated with Master Chemical Mechanism, Atmos. Environ., 41, 2570-2579, 2007a.

Derwent, R. G., Jenkin, M. E., Passant, N. R., and Pilling, M. J.: Reactivity-based strategies for photochemical ozone control in Europe, Environ. Sci. Policy, 10, 445-453, 2007b.

Derwent, R. G., Jenkin, M. E., Saunders, S. M., Pilling, M. J., Simmonds, P. G., Passant, N. R., Dollard, G. J., Dumitrean, P., and Kent, A.: Photochemical ozone formation in north west Europe and its control, Atmos. Environ., 37, 1983-1991, 2003.

Dommen, J., Metzger, A., Duplissy, J., Kalberer, M., Alfarra, M. R., Gascho, A., Weingartner, E., Prevot, A. S. H., Verheggen, B., and Baltensperger, U.: Laboratory observation of oligomers in the aerosol from isoprene/NOx photooxidation, Geophys. Res. Lett., 33(13), L13805, doi:10.1029/2006GL026523, 2006.

Edney, E. O., Kleindienst, T. E., Jaoui, M., Lewandowski, M., Offenberg, J. H., Wang, W., and Claeys, M.: Formation of 2-methyl tertrols and 2-methylglyceric acid in secondary organic aerosol from laboratory irradiated isoprene/ $\mathrm{NO}_{\mathrm{X}} / \mathrm{SO}_{2} /$ air mixtures and their detection in ambient $\mathrm{PM}_{2.5}$ samples collected in the eastern United States, Atmos. Environ., 39, 5281-5289, 2005.

Finlayson-Pitts, B. J. and Pitts Jr., J. N.: Chemistry of the Upper and Lower Atmosphere, Academic Press, 2000

Fisseha, R., Dommen, J., Sax, M., Paulsen, D., Kalberer, M., Maurer, R., Hofler, F., Weingartner, E., and Baltensperger, U.: Identification of Organic Acids in Secondary Organic Aerosol and the Corresponding Gas Phase from Chamber Experiments, Anal. Chem., 76(22), 6535-6540, 2004.

Fleming, Z. L., Monks, P. S., Rickard, A. R., Bandy, B. J., Brough, N., Green, T. J., Reeves, C. E., and Penkett, S. A.: Seasonal dependence of peroxy radical concentrations at a Northern hemisphere marine boundary layer site during summer and winter: evidence for radical activity in winter, Atmos. Chem. Phys., 6, 5415-5433, 2006b,

http://www.atmos-chem-phys.net/6/5415/2006/.

Fleming, Z. L., Monks, P. S., Rickard, A. R., Heard, D. E., Bloss, W. J., Seakins, P. W., Still, T. J., Sommariva, R., Pilling, M. J., Morgan, R., Green, T. J., Brough, N., Mills, G. P., Penkett, S. A., Lewis, A. C., Lee, J. D., Saiz-Lopez, A., and Plane, J. M. C.: Peroxy radical chemistry and the control of ozone photochemistry at Mace Head, Ireland during the summer of 2002, Atmos. Chem. Phys., 6, 1-22, 2006a, http://www.atmos-chem-phys.net/6/1/2006/.

Forstner, H. J. L., Flagan, R. C., and Seinfeld, J. H.: Secondary Organic Aerosol from Photooxidation of Aromatic Hydrocarbons: Molecular Composition, Environ. Sci. Technol., 31, 1345-1358, 1997.

Friedrich, R. and Obermeier, A.: Anthropogenic Emissions of Volatile Organic Compounds, Reactive Hydrocarbons in the Atmosphere, H. C. N. London, Academic Press, 2-38, 1999.

Gao, S., Ng, N. L., Keywood, M., Varutbangkul, V., Bahreini, R., Nenes, A., He, J., Yoo, K. Y., Beauchamp, J. L., Hodyss, R. P., Flagan, R. C., and Seinfeld, J. H.: Particle Phase Acidity and Oligomer Formation in Secondary Organic Aerosol, Environ. Sci. Technol., 38, 6582-6589, 2004.
Green, T. J., Reeves, C. E., Fleming, Z. L., Brough, N., Rickard, A. R., Bandy, B. J., Monks, P. S., and Penkett, S. A.: An improved dual channel PERCA instrument for atmospheric measurements of peroxy radicals, J. Environ. Monitor., 8, 530-536, 2006.

Grosjean, D.: Insitu organic aerosol formation during a smog episode- estimated production and chemical funstionality, Atmos. Environ., 26A, 953-963, 1992.

Gross, D. S., Galli, M. E., Kalberer, M., Prevot, A. S. H., Dommen, J., Alfarra, M., Duplissy, J., Gaeggeler, K., Gascho, A., Metzger, A., and Baltensperger, U.: Real-Time Measurement of Oligomeric Species in Secondary Organic Aerosol with the Aerosol Time-of-Flight Mass Spectrometer, Anal. Chem., 8, 2130-2137, 2006.

Hamilton, J. F., Lewis, A. C., Bloss, C., Wagner, V., Henderson, A. P., Golding, B. T., Wirtz, K., Martin-Reviejo, M., and Pilling, M. $\mathrm{J}$.: Measurments of photo-oxidation products from the reaction of a series of alkyl-benzenes with hydroxyl radicals during EXACT using comprehensive gas chromatography, Atmos. Chem. Phys., 3, 1999-2014, 2003

Hansel, A. and Wisthaler, A.: A Method for Real-Time Detection of PAN, PPN and MPAN in Ambient Air, Geophys. Res. Lett., 27(6), 895-898, 2000.

Havers, N., Burba, P., Lambert, J., and Klockow, D.: Spectroscopic Characterization of HumicLike Substances in Airborne Particulate Matter, J. Atmos. Chem., 29, 45-54, 1998.

Holmes, N. S.: A review of particle formation events and growth in the atmosphere in the various environments and discussion of mechanistic implications, Atmos. Environ., 41, 2183-2201, 2007.

IPCC: Intergovernmental Panel on Climate Change, Fourth Assessment Report, Climate Change 2007, 2007.

Izumi, K., Murano, K., Mizuochi, M., and Fukuyama, T.: Aerosol Formation by the Photooxidation of Cyclohexene in the Presence of Nitrogen Oxides, Environ. Sci. Technol., 22, 1207-1215, 1998.

Jang, M. and Kamens, R. M.: Atmospheric Secondary Aerosol Formation by Heterogeneous Reactions of Aldehydes in the Presence of a Sulfuric Acid Aerosol Catalyst, Environ. Sci. Technol., 35, 4758-4766, 2001.

Jang, M., Lee, S., and Kamens, R. M.: Organic aerosol growth by acid-catalyzed heterogeneous reactions of octanal in a flow reactor, Atmos. Environ., 37(15), 2125-2138, 2003.

Jenkin, M. E., Saunders, S. M., Wagner, V., and Pilling, M. J.: Protocol for the development of the Master Chemical Mechanism MCM v3 (Part B): tropospheric degredation of aromatic volatile organic compounds, Atmos. Chem. Phys., 3, 181-193, 2003, http://www.atmos-chem-phys.net/3/181/2003/.

Johnson, D., Jenkin, M. E., Wirtz, K., and Martin-Reviejo, M.: Simulating the Formation of Secondary Organic Aerosol from the Photooxidation of Toluene, Environ. Chem., 1, 150-165, 2004.

Johnson, D., Jenkin, M. E., Wirtz, K., and Martin-Reviejo, M.: Simulating the Formation of Secondary Organic Aerosol from the Photooxidation of Aromatic Hydrocarbons, Environ. Chem., 2, 35-48, 2005.

Kalberer, M., Paulsen, D., Sax, M., Steinbacher, M., Dommen, J., Prevot, A. S. H., Fisseha, R., Weingartner, E., Frankevich, V., Zenobi, R., and Baltensperger, U.: Identification of polymers as major components of atmospheric organic aerosols, Science, 303(5664), 1659-1662, 2004. 
Kalberer, M., Sax, M., and Samburova, V.: Molecular Size Evolution of Oligomers in Organic Aerosols Collectes in Urban Atmospheres and Generated in a Smog Chamber, Environ. Sci. Technol., 40, 5917-5922, 2006.

Kanakidou, M., Seinfeld, J. H., Pandis, S. N., Barnes, I., Detener, F. J., Facchini, M. C., Van Dingenen, R., Ervens, B., Nenes, A., Nielsen, C. J., Swietlicki, E., Putaud, J. P., Balkanski, Y., Fuzzi, S., Horth, J., Moortgat, G. K., Winterhalter, R., Myhre, C. L., Tsigaridis, K., Vignati, E., Stephanou, E. G., and Wilson, J.: Organic aerosol and global climate modelling: a review, Atmos. Chem. Phys., 5, 1053-1123, 2005,

http://www.atmos-chem-phys.net/5/1053/2005/.

Kleindienst, T. E., Edney, E. O., Lewandowski, M., Offenberg, J. H., and Jaoui, M.: Secondary Organic Carbon and Aerosol Yields from the Irradiations of Isoprene and r-Pinene in the Presence of NOx and SO2, Environ. Sci. Technol., 40(12), 38073812, 2006.

Kleindienst, T. E., Smith, D. F., Li, W., Edney, E. O., Driscoll, D. J., Speer, R. E., and Weathers, W. S.: Secondary organic aerosol formation from the oxidation of aromatic hydrocarbon in the presence of dry submicron ammonium sulfate aerosol, Atmos. Environ., 33, 3669-3681, 1999.

Limbeck, A., Kulmala, M., and Puxbaum, H.: Secondary organic aerosol formation in the atmosphere via heterogeneous reaction of gaseous isoprene on acid particles, Geophys. Res. Lett., 30(19), 1996, doi:10.1029/2003GL017738, 2003.

Lindinger, W., Hirber, J., and Paretzke, H.: An ion/moleculereaction mass spectrometer used for on-line trace gas analysis, Int. J. Mass Spectrom., 129, 79-88, 1993

Metzger, A., J. Dommen, K. Gaeggeler, J. Duplissy, A. S. H. Prevot, J. Kleffmann, Y. Elshorbany, A. Wisthaler and B. U.: Evaluation of 1,3,5-trimethylbenzene degredation in the detailed tropospheric chemistry mechanism MCMv3.1 using environmental chamber data, Atmos. Chem. Phys., 9(21), 6453-6468, 2008a.

Metzger, A., Verheggen, B., Duplissy, J., Gaeggeler, K., Dommen, J., Prevot, A. S. H., and Baltensperger, U.: Influence of sulfur dioxide on nucleation, growth rates and yield of secondary organic aerosol, in preparation, 2008b.

Monks, P. S.: Gas-phase radical chemistry in the troposphere, Chem. Soc. Rev., 34(5), 376-395, 2005.

Monks, P. S., Carpenter, L. J., Penkett, S. A., Ayers, G. P., Gillett, R. W., Galbally, I. E., and Meyer, C. P.: Fundamental ozone photochemistry in the remote marine boundary layer: The SOAPEX experiment, measurement and theory, Atmos. Environ., 32(21), 3647-3664, 1998.

Næs, T. and Martens, H.: Pricnipal Component Regression in NIR analysis view points background details and selection components, J. Chemometr., 2(2), 155-168, 1988.

Ng, N. L., Kroll, J. H., Chan, A. W. H., Chhabra, P. S., Flagan, R. C., and Seinfeld, J. H.: Secondary Organic Aerosol Fromation from $m$-xylene, toluene, and benzene, Atmos. Chem. Phys., 7, 4085-4126, 2007,

http://www.atmos-chem-phys.net/7/4085/2007/.

Ng, N. L., Kroll, J. H., Keywood, M., Bahreini, R., Varutbangkul, V., Flagan, R. C., and Seinfeld, J. H.: Contribution of First- versus Second-Generation Products to Secondary Organic Aerosols Formed in the Oxidation of Biogenic Hydrocarbons, Environ. Sci. Technol., 40, 2283-2297, 2006.
Northcross, A. L. and Jang, M.: Heterogeneous SOA yield from ozonolysis of monoterpenes in the presence of inorganic acid, Atmos. Environ., 41(7), 1483-1493, 2007.

Odum, J. R., Hoffman, T., Bowman, F., Collins, D., Flagan, R. C., and Seinfeld, J. H.: Gas/Particle Partitioning and Secondary Organic Aerosol Yields, Environ. Sci. Technol., 30, 2580-2585, 1996.

Odum, J. R., Jungkamp, T. P. W., Griffin, R. J., Flagan, R. C., and Seinfeld, J. H.: The Atmospheric Aerosol-Formation Potential of Whole Gasoline Vapor, Science, 276, 96-99, 1997.

Parker, A. P.: Measurements of Peroxy Radicals using the Peroxy Radical Chemical Amplification Technique, Department of Chemistry, Leicester, University of Leicester, Ph.D. thesis, 2007.

Paulsen, D., Dommen, J., Kalberer, M., Prevot, A. S. H., Richter, R., Sax, M., Steinbacher, M., Weingartner, E., and Baltensperger, U.: Secondary organic aerosol formation by irradiation of 1,3,5trimethylbenzene-NOx-H2O in a new reaction chamber for atmospheric chemistry and physics, Environ. Sci. Technol., 39(8), 2668-2678, 2005.

Rickard, A. R., Wyche, K. P., Metzger, A., Monks, P. S., Ellis, A. M., and Pilling, M. J.: Model-measurement comparisons of the evolution of the gas-phase precursors to secondary organic aerosol formed in the photooxidation of 1,3,5-trimethylbenzene, Atmos. Chem. Phys., in preparation, 2009.

Sax, M., Zenobi, R., Baltensperger, U., and Kalberer, M.: Time Resolved Infrared Spectroscopic Analysis of Aerosol Formed by Photooxidation of 1,3,5-Trimethylbenzene and $\alpha$-Pinene, Aerosol Sci. Tech., 39, 822-830, 2005.

Seinfeld, J. H. and Pankow, J. F.: Organic Atmospheric Particulate Material, Annu. Rev. Phys. Chem., 54, 121-140, 2003.

Smith, D. F., Kleindienst, T. E., and McIver, C. D.: Primary Production Distributions from the Reactions of $\mathrm{OH}$ with m-,p-Xylene, 1,2,4- and 1,3,5-Trimethylbenzene, J. Atmos. Chem., 34, 339364, 1999.

Song, C., Kwangsam, N., and Cocker, D. R.: Impact of the Hydrocarbon to NOx Ratio on Secondary Organic Aerosol Formation, Environ. Sci. Technol., 39, 3143-3149, 2005.

Stern, J. E., Flagan, R. C., Grosjean, D., and Seinfeld, J. H.: Aerosol Formation and Growth in Atmospheric Aromatic Hydrocarbon Oxidation, Environ. Sci. Technol., 21(12), 1224-1231, 1987.

Stroud, C. A., Makar, P. A., Michelangeli, D. V., Mozurkewich, M., Hastie, D. R., Barbu, A., and Humble, J.: Simulating Organic Aerosol Formation during the Photoxidation of Toluene/NOx Mixtures: Comparing the Equilibrium and Kinetic Assumptions, Environ. Sci. Technol., 38, 1471-1479, 2004.

Surratt, J. D., Lewandowski, M., Offenberg, J. H., Jaoui, M., Kleindienst, T. E., Edney, E. O., and Seinfeld, J. H.: Effect of acidity on secondary organic aerosol formation from isoprene, Environ. Sci. Technol., 41(15), 5363-5369, 2007.

Surratt, J. D., Murphy, S. M., Kroll, J. H., Ng, N. L., Hilderbrandt, L., Sorooshian, A., Szmigielski, R., Vermeylen, R., Maenhaut, W., Claeys, M., Flagen, R., and Seinfeld, J. H.: Chemical Composition of Secondary Organic Aerosol Formed from the Photooxidation of Isoprene, J. Phys. Chem. A, 110, 9665-9690, 2006.

Taira, M. and Yukio, K.: Continuous Generation System for LowConcentration Gaseous Nitrous Acid, Anal. Chem., 62, 630-633, 1990. 
Tolocka, M. P., Jang, M., Ginter, J. M., Cox, F. J., Kamens, R. M., and Johnston, M. V.: Formation of Oligomers in Secondary Organic Aerosol, Environ. Sci. Technol., 38, 1428-1434, 2004.

Tsigaridis, K. and Kanakidou, M.: Global modelling of secondary organic aerosol in the troposhere: A sensitivity analysis, Atmos. Chem. Phys. Discuss., 3, 2879-2929, 2003,

http://www.atmos-chem-phys-discuss.net/3/2879/2003/.

Verheggen, B., Mozurkewich, M., Caffrey, P., Frick, G., Hoppel, W., and Sullivan, W.: alpha-Pinene oxidation in the presence of seed aerosol: Estimates of nucleation rates, growth rates, and yield, Environ. Sci. Technol., 41(17), 6046-6051, 2007.
Wyche, K. P., Blake, R. S., Ellis, A. M., Monks, P. S., Brauers, T., Koppman, R., and Apel, E.: Performance of a Chemical Ionisation Reaction Time-of-Flight Mass Spectrometer (CIR-TOFMS) for the Measurement of Atmospherically Significant Oxygenated Volatile Organic Compounds, Atmos. Chem. Phys., 7, 609-620, 2007,

http://www.atmos-chem-phys.net/7/609/2007/.

Yu, J., Jeffries, H. E., and Sexton, K. G.: Atmospheric Photooxidation of Alkylbenzenes-I. Carbonyl Product Analysis, Atmos. Environ., 31(15), 2261-2280, 1997. 